\title{
Compositional dynamics of suspended sediment in the Rhine River: sources and controls
}

\author{
Marcel van der Perk ${ }^{1}$ (D) Alvaro Espinoza Vilches ${ }^{1}$
}

Received: 6 May 2019 / Accepted: 5 October 2019 / Published online: 13 December 2019

(C) The Author(s) 2019

\begin{abstract}
Purpose Information on the geochemical composition of suspended sediments in rivers is crucial to identify sediment source type or area. In large river basins, however, the relation between sediment composition and its controlling factors is often obscured. This study aims to assess and improve the conceptual understanding on the factors and mechanisms that control the composition of suspended sediments in the River Rhine, one of the large European rivers, and to identify the dominant source types of elements.

Materials and methods We performed log-linear regression analysis and principal component analysis (PCA) on bi-weekly monitoring data of suspended sediment composition, supplemented with daily measurements of suspended sediment concentrations (SSC) and discharge at the Lobith monitoring station near the German-Dutch border for the period 2011-2016.

Results and discussion The statistical analyses show a consistent grouping of elements that display contrasting temporal variation or different responses to increased discharge. The contrasting behaviour also becomes manifest in the results from the PCA. A first component that explains about the half of the total variance in the entire dataset reflects the variation in clay content in the suspended sediment. A second component reflects anthropogenic pollution and explains about a quarter of the total variance. A third component probably reflects variation in sediment provenance.

Conclusions The majority of the temporal variation in suspended sediment composition can be attributed to variations in grain size (clay content), organic matter content, and anthropogenic pollution. Only a minority of the variation can be attributed to variations in the contributions from different upstream source areas. This variation represented by the third and higher components from the PCA can potentially be used for sediment provenance analysis.
\end{abstract}

Keywords Concentration-discharge relationships $\cdot$ Principal component analysis $\cdot$ Rare earth elements $\cdot$ Suspended sediment

\section{Introduction}

The transport of sediment through the river system to seas and oceans is a fundamental process in the denudation of continents and the formation of deltas and coasts (Walling 2006). In

Responsible editor: Alexander Koiter

Electronic supplementary material The online version of this article (https://doi.org/10.1007/s11368-019-02490-5) contains supplementary material, which is available to authorized users.

Marcel van der Perk

m.vanderperk@uu.nl

1 Department of Physical Geography, Utrecht University, P.O. Box 80.115, 3508, TC Utrecht, the Netherlands the past decades, the sediment loads in many rivers across the globe have substantially decreased as a consequence of the construction of reservoirs and dams and sediment mining (Syvitski et al. 2005). This has led and leads to severe sediment shortage problems in downstream areas including drowning of deltas and loss of coastal land because the sediment supply is insufficient to compensate land subsidence and sea level rise (Syvitski et al. 2009).

Sediment transported by rivers comprises resistant primary minerals (e.g. quartz, zircon), secondary minerals (e.g. clays, oxyhydroxides and carbonates) produced from physical and chemical weathering of bedrock, and terrestrially derived or internally produced organic matter (Eisma 1993; Viers et al. 2009). The majority of sediment transported in rivers consists of suspended sediment, which is finer than sediment in the bed load modes of transport. As fine sediments generally contain a 
variety of elements other than silicon, the transport of fine suspended sediments contributes significantly to global elemental cycles and the transfer of pollutants from terrestrial to coastal and marine systems (Owens et al. 2005; Walling 2006). The load of sediments and associated substances in rivers is strongly controlled by discharge, not only because the load is the product of concentration and discharge, but also because the sediment concentration generally increases with discharge (Van der Perk 2013). Therefore, discharge events are very important for sediment transport and geochemical fluxes. For example, Ollivier et al. (2015) found that discharge events that represent less than $12 \%$ of the time were responsible for 69 to $91 \%$ of the annual sediment-associated element fluxes in the Rhône River in France.

Information on the elemental composition of suspended sediments in rivers has demonstrated to be crucial to identify sediment source type or source area (Förstner and Salomons 1980; Collins et al. 1997; Belmont et al. 2011; Haddadchi et al. 2013; Smith and Blake 2016; Collins et al. 2017) or to assess anthropogenic contamination of sediments (Salomons and Förstner 1980; Benson et al. 2016; Zhao et al. 2017). Geographic differences in the element concentrations in suspended sediment are mostly related to differences in parent material, weathering types and rates, river discharge, organic matter content, and additional natural or anthropogenic sources, including inputs of aerosols and diffuse and point source contaminant inputs, between catchments or river basins (Martin and Meybeck 1979; Savenko 2007). The elemental composition of suspended sediment shows generally less variability in time than in space (Nasrabadi et al. 2018; Rügner et al. 2019), although the sediment composition may change considerable in response to individual discharge events (e.g. Vale 1990; Schleichert and Keller 1997; Coynel et al. 2007; Berner et al. 2012; Pulley et al. 2016). Both long- and shortterm temporal variations in the suspended sediment composition are mostly linked to variations in sediment supply from different source areas with different bedrock and associated weathering types and rates, variations in direct inputs of anthropogenic contaminants, remobilisation of previously deposited polluted sediments and variations in particle size and organic matter content of the suspended sediment (Van der Weijden and Middelburg 1989; Zwolsman and Van Eck 1999; Quinton and Catt 2007; Ma et al. 2015; Van der Perk 2013; Hamers et al. 2015; Rügner et al. 2019). Thus, to reliably quantify contaminant transport, detailed information on the temporal variation in sediment composition is essential.

The variability of sources of sediments and contaminant inputs into rivers and the transient and intermittent nature of sediment transport cause the relation between observed sediment composition and its controlling factors and processes to become obscured and complex. This particularly applies to large river basins, because of their large variability in sediment and contaminant inputs and relatively long transport distances along which physical and chemical transformation of the sediment may take place. As a result, the identification of sediment sources becomes complicated. Hence, the selection of appropriate fingerprints and tracers of sediment (e.g. Collins et al. 2010; Smith and Karam Lennard 2018) requires a fundamental insight in the factors and processes that control the composition of sediment in large river basins.

This study aims to assess and improve the conceptual understanding on the factors and mechanisms that control the element composition of suspended sediments in one of the large European rivers, the River Rhine, and to identify the dominant source types of elements (i.e. anthropogenic vs. geogenic sources). For this, we used existing monitoring data on suspended sediment composition in the Rhine River at the Lobith monitoring station in the Netherlands near the German-Dutch border for the period 2011-2016. We related the chemical composition of suspended sediments to discharge and physical sediment parameters including organic carbon and clay content and examined its seasonal variation.

\section{Materials and methods}

\subsection{Study area}

The Rhine River rises in the Swiss Alps and flows through Switzerland along the Swiss-Liechtenstein, Swiss-Austrian, Swiss-German, German-French borders through Germany and the Netherlands into the North Sea (Fig. 1). It has an approximate length of $1230 \mathrm{~km}$ (Görgen et al. 2010) and a drainage basin of about $185,000 \mathrm{~km}^{2}$. The Rhine River basin covers five geologic-tectonic zones (Preusser 2008; Frings et al. 2014a, b): the Alps, the High Rhine, the Upper Rhine Graben, the Rhenish Massif, the Lower Rhine Embayment and the Rhine Delta. The Alps are primarily made up of Palaeozoic crystalline and metamorphic rocks and Mesozoic and Cenozoic sedimentary (mostly calcareous) rocks which were folded and uplifted during the Alpine orogeny (Cretaceous-Eocene) as a result of the collision of the Adriatic and the European plates. The Upper Rhine Graben and Lower Rhine Embayment were formed due to tectonic subsidence resulting from compressional stresses in relation to the alpine uplift and belong to the European rift System (Preusser 2008). In these areas, the surface geology is characterised by unconsolidated Quaternary sands and gravels. The Upper Rhine Graben is predominantly flanked by Palaeozoic crystalline rocks and Triassic sedimentary rocks. In between the Upper Rhine Graben and Lower Rhine Embayment, the Rhenish Massif forms an upland range largely built up by sedimentary rocks (mostly shales, schists and sandstone) of Devonian and Carboniferous age and which was uplifted following the Alpine orogeny (Preusser 2008). 
Fig. 1 The Rhine River basin

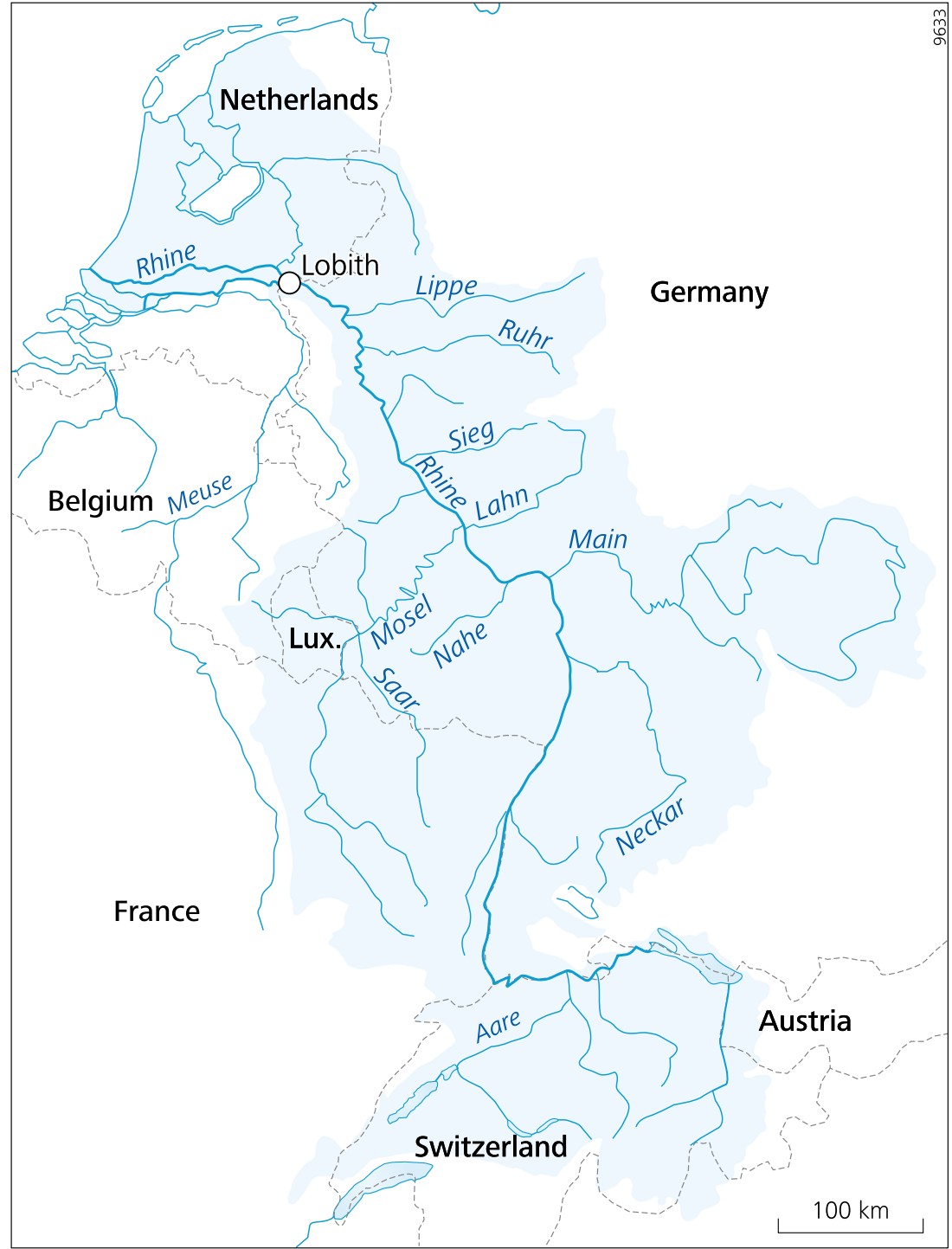

The Rhine delta apex is located near the German-Dutch border. In the Rhine delta zone, the river splits into three major distributaries (Waal, Nederrijn-Lek, and IJssel). The Rhine River has an average discharge of $2300 \mathrm{~m}^{3} \mathrm{~s}^{-1}$ at the German-Dutch border (Uehlinger et al. 2009). Its main tributary rivers are the rivers Aare, Ill, Neckar, Main, Lahn, Moselle and Ruhr. The alpine Rhine represents $19 \%$ of the catchment area, but delivers nearly half of the discharge on average (Hartmann et al. 2007); and its discharge is characterized by a snowmelt regime. The discharge regime in midmountain ranges and lowland regions feeding the Rhine River downstream the Swiss-German-French border is raindominated.

Today, about 58 million people live in the Rhine River basin, of which $60 \%$ lives in Germany and $20 \%$ in the Netherlands (Uehlinger et al. 2009). Large urban and metropolitan areas and associated industries are located around Basel (Switzerland), Mannheim, Frankfurt/Mainz, between
Cologne and Duisburg (Ruhr area) and around Rotterdam (the Netherlands).

\subsection{Monitoring data}

For this study, we used bi-weekly monitoring data of suspended sediment composition, supplemented with daily measurements of suspended sediment concentrations (SSC) and discharge at the Lobith monitoring station near the German-Dutch border from the regular monitoring programme of Rijkswaterstaat (the water authority of the Dutch Ministry of Infrastructure and Water Management) (Rijkswaterstaat 2019). The basic data is provided in Online Resource 1 (Electronic Supplementary Material). The Lobith monitoring station is the primary monitoring station for discharge and water quality in the Rhine River in the Netherlands. It is located about $5 \mathrm{~km}$ upstream from the 
location where the Rhine River bifurcates into various distributaries.

Sampling, storage, preparation and analysis of suspended sediment are carried out according to standard protocols, which are summarised in Table 1 and described in further detail by Epema and Zemmelink (2017). Water samples for the measurement of SSC are collected daily from the thread of the river and transported and stored in $1000 \mathrm{ml}$ polyethylene bottles under cool (about $4{ }^{\circ} \mathrm{C}$ ) and dark conditions. In the laboratory, the water samples are filtered through a $0.45-\mu \mathrm{m}$ membrane filter and dried at $105{ }^{\circ} \mathrm{C}$. Bi-weekly suspended sediment samples for physico-chemical analysis are collected using a continuous flow centrifuge (17,000 rotations per minute; flow rate $1000 \pm 40 \mathrm{~L} \mathrm{~s}^{-1}$ ). The suspended sediment samples are transported and stored in 800-ml glass bottles under cool and dark conditions. In the laboratory, the samples are freeze-dried and homogenised. Aliquots are taken for the determination of the grain size distribution and organic carbon content, and elemental analysis using ICP-MS (see Table 1). The aliquot for elemental analysis is milled and about $250 \mathrm{mg}$ is subsequently, digested using $10 \mathrm{ml}$ ultrapure nitric acid in a microwave at $150{ }^{\circ} \mathrm{C}$. Grain size analysis is performed after removal of organic matter, carbonates and free iron oxide.

The compositional data used in this study included clay $(<$ $2 \mu \mathrm{m})$ and organic carbon content and concentrations of the following 53 elements including trace metals and rare earth elements (REEs): $\mathrm{Li}, \mathrm{Na}, \mathrm{K}, \mathrm{Rb}, \mathrm{Cs}, \mathrm{Be}, \mathrm{Mg}, \mathrm{Ca}, \mathrm{Sr}, \mathrm{Ba}, \mathrm{Y}, \mathrm{La}$, $\mathrm{Ce}, \mathrm{Pr}, \mathrm{Nd}, \mathrm{Sm}, \mathrm{Eu}, \mathrm{Gd}, \mathrm{Tb}, \mathrm{Dy}, \mathrm{Ho}, \mathrm{Er}, \mathrm{Tm}, \mathrm{Yb}, \mathrm{Lu}, \mathrm{Th}, \mathrm{U}$, $\mathrm{Ti}, \mathrm{Zr}, \mathrm{V}, \mathrm{Nb}, \mathrm{Cr}, \mathrm{Mo}, \mathrm{W}, \mathrm{Mn}, \mathrm{Fe}, \mathrm{Co}, \mathrm{Ni}, \mathrm{Cu}, \mathrm{Ag}, \mathrm{Zn}, \mathrm{Cd}, \mathrm{Hg}$, $\mathrm{Al}, \mathrm{Ga}, \mathrm{Tl}, \mathrm{Ge}, \mathrm{Sn}, \mathrm{Pb}, \mathrm{P}, \mathrm{As}, \mathrm{Sb}$ and Te. We used the available data for the period 2011-2016 ( $n=153)$, since 2011 the chemical composition analysis of suspended sediments has been extended to include REEs and other trace elements. This period is hydrologically characterised by the occurrence of five discharge events with peak discharges greater than $6000 \mathrm{~m}^{3}$ $\mathrm{s}^{-1}$ (recurrence time approximately 2 years (Hegnauer et al. 2014)), of which one had a peak discharge of greater than $8000 \mathrm{~m}^{3} \mathrm{~s}^{-1}$ (recurrence time approximately 9 years)
(Fig. 2), and a mean discharge of $2190 \mathrm{~m}^{3} \mathrm{~s}^{-1}$, which is slightly lower than the long-term mean discharge.

\subsection{Concentration rating curves}

The response of the elemental composition of suspended sediment to discharge variations was explored using a rating curve approach. A rating curve represents a concentrationdischarge relationship, which generally take the form a power-law function

$C=\alpha Q^{\beta}$

Where $C=$ concentration (usually expressed in $\mathrm{mg}^{-1}$ ); $Q=$ river discharge (usually expressed in $\mathrm{m}^{3} \mathrm{~s}^{-1}$ ), $\alpha$ and $\beta$ are the rating curve parameters.

Rating curves are traditionally used to estimate suspended sediment concentrations (Colby 1956; Walling 1977; Asselman 2000; Syvitsky et al. 2000), solute concentrations from discharge measurements (Carling 1983; Moatar et al. 2017; Rose et al. 2018), but the same approach can also be used to predict the concentrations of substances on suspended sediment (Droppo and Jaskot 1995; Rondeau et al. 2005), which are usually expressed in $\mathrm{mg} \mathrm{kg}^{-1}$.

The rating curve parameters $\alpha$ and $\beta$ were estimated using linear regression between the log-transformed (base 10) concentrations and the log-transformed discharge. Parameter $\alpha$ was bias-corrected according to Ferguson (1986):

$\alpha=10^{a} \times \exp \left(2.65 s^{2}\right)$

Where $a=$ the intercept of the regression $\operatorname{line}(\log C=a+\beta$ $\log Q$ ) and $s=$ standard error of the regression.

The residuals of the rating curve were related to the sediment physical parameters including organic matter and clay content and were monthly averaged to examine the seasonal variation in the concentration-discharge relation.
Table 1 Short description of measurement and analysis methods of discharge and suspended sediment concentration and composition in the Rhine River at the Lobith monitoring station. For a detailed description of the procedures of sampling, storage, preparation and analysis, see Epema and Zemmelink (2017) and references therein

\begin{tabular}{llll}
\hline Parameter & Unit & Protocol & Short description \\
\hline Discharge & $\mathrm{m}^{3} \mathrm{~s}^{-1}$ & & Discharge-stage relationship \\
Suspended sediment concentration (SSC) & $\mathrm{mg} \mathrm{l}^{-1}$ & NEN 6484 & Filtration through a 0.45 $\mu$ m membrane filter \\
Clay $(<2 \mu \mathrm{m})$ content in suspended sediment (SS) & $\%$ & NEN 5753 & Determination of grain size distribution by pipet method \\
Organic C in SS & $\%$ & NEN 5756 & Measurement of carbon dioxide formation \\
& & & after dry combustion after removal of carbonates \\
$\begin{array}{l}\text { Element concentrations including trace metals (except Hg), } \\
\text { REEs, and Total P in SS }\end{array}$ & $\mathrm{mg} \mathrm{kg}^{-1}$ & ISO 17294-2 & Inductively coupled plasma mass spectrometry (ICP-MS) \\
Hg concentration in SS & $\mathrm{mg} \mathrm{kg}^{-1}$ & & Cold-vapour-isotope dilution-ICP-MS \\
\hline
\end{tabular}




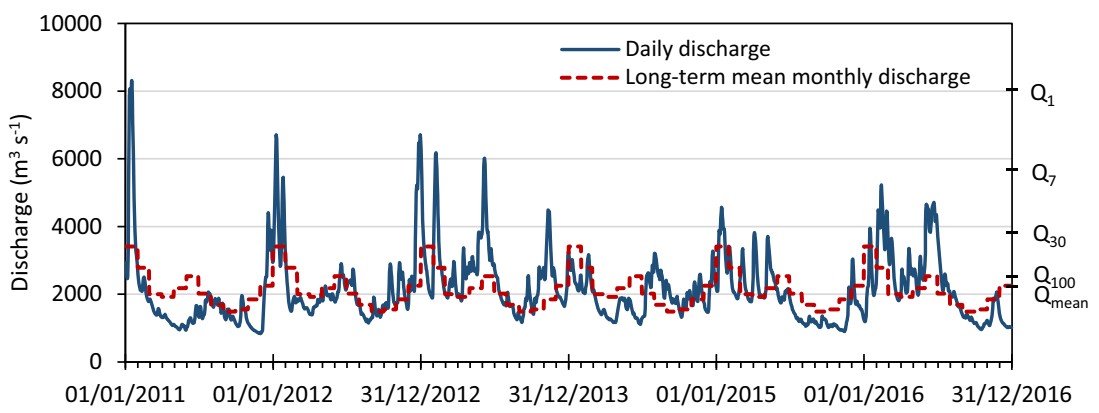

Fig. 2 Daily and long-term mean monthly discharge at the Lobith monitoring station for the period 2011-2016. For reference, the following long-term (1901-2016) statistics are plotted on the secondary y-axis: average discharge $\left(\mathrm{Q}_{\text {mean }}\right)$ and the discharge with an exceedance

\subsection{Principal component analysis}

To identify the primary processes controlling the temporal variation in the chemical composition of suspended sediment and their relative contribution to the total variation in the data, a principal component analysis (PCA) was conducted using the R-stats package (version 3.4.3) princomp function (R Core Team 2017). The PCA based was performed on the correlation matrix, which is equivalent to a PCA on the Z-normalised concentrations (i.e. with zero mean and unit variance). At first instance, we performed the PCA on the untransformed element concentrations. This approach implicitly assumes that the sediment composition is primarily controlled by linear mixing of different sediment sources and that geochemical transformation processes during transport including weathering, which may give rise to non-linear deviations from the linear mixture, play a minor role. Transformation of the concentration data, e.g. by taking their natural logarithm or by Al-normalisation would violate this assumption. As concentration data are essentially compositional (closed) data (Aitchison 1986), the application of statistical methods to untransformed concentration data may be problematic. In order to apply any statistical method, the data should fulfil the conditions of scale invariance and subcompositional coherence (Pawlowsky-Glahn et al. 2007). In our study, these conditions are largely met because the concentration data were obtained using standard protocols and expressed in standard units of measure, i.e. dry-weight concentrations in the entire suspended sediment sample. Furthermore, closed concentration data are subject to simplex constraints, which makes the concentrations of mutually dependent. A preliminary evaluation of the concentrations data used for our study shows that the oxides of all above elements only represent a minor proportion $(23.3 \% \pm 1.9 \%$ of the total weight $)$ of the sediment. This implies that the effect of this constraint on the mutual dependence of the concentrations is limited. frequency of $100 \mathrm{~d} \mathrm{y}^{-1}\left(\mathrm{Q}_{100}\right)$ (corresponding to an exceedance probability of $27.4 \%), 30 \mathrm{~d} \mathrm{y}^{-1}\left(\mathrm{Q}_{30}\right)(8.2 \%), 7 \mathrm{~d} \mathrm{y}^{-1}\left(\mathrm{Q}_{7}\right)(1.9 \%)$ and 1 $\mathrm{d} \mathrm{y}^{-1}\left(\mathrm{Q}_{1}\right)(0.3 \%)$

For comparison, we also performed a PCA on the concentration data normalised to $\mathrm{Al}$ and organic $\mathrm{C}$. Normalisation to $\mathrm{Al}$ was achieved by calculating the dimensionless element/Al ratio. Normalisation to organic $\mathrm{C}$ was achieved by calculating:

$C_{\text {norm } \_O C}=\frac{(100-2 \times \overline{O C}) \times C}{(100-2 \times O C)}$

Where $C_{\text {norm } \_O C}=$ organic-C-normalised concentration (mg $\left.\mathrm{kg}^{-1}\right), \overline{O C}=$ average organic $\mathrm{C}$ content of all sediment samples (\%), $O C=$ average organic $\mathrm{C}$ content $(\%)$, and $C=$ element concentration $\left(\mathrm{mg} \mathrm{kg}^{-1}\right)$.

\section{Results}

\subsection{Monitoring data}

Table 2 shows the means, standard deviations and correlation matrix of the monitoring data including the element concentrations (arranged according the columns of the periodic table of elements), river discharge, SSC, and the clay and organic C of the suspended sediment. For comparison, the mean and standard deviations of the element concentrations (except Be and Ag) in the world rivers (Viers et al. 2009) are also listed. A limited selection of bivariate scatter plots of element concentrations is presented in Online Resource 2 (Electronic Supplementary Material).

The scatter plots displayed in Online Resource 1 (Electronic Supplementary Material) show that the elements are approximately linearly related, particularly those elements that are mutually positively correlated. The correlation matrix reveals a number of visually distinct groups of elements that display mutually positively correlated patterns of temporal variation. The most notable group consist of the elements $\mathrm{Li}$, $\mathrm{K}, \mathrm{Rb}, \mathrm{Cs}, \mathrm{Be}, \mathrm{Mg}, \mathrm{Y}, \mathrm{Ce}, \mathrm{Br}, \mathrm{Nd}, \mathrm{Eu}, \mathrm{Gd}, \mathrm{Tb}, \mathrm{Dy}, \mathrm{Ho}, \mathrm{Er}, \mathrm{Tm}$, $\mathrm{Yb}, \mathrm{Lu}, \mathrm{Th}, \mathrm{U}, \mathrm{V}, \mathrm{Fe}, \mathrm{Co}, \mathrm{Ni}, \mathrm{Al}, \mathrm{Ga}$ and $\mathrm{Tl}$, which are traditionally linked to clay minerals. These elements are 


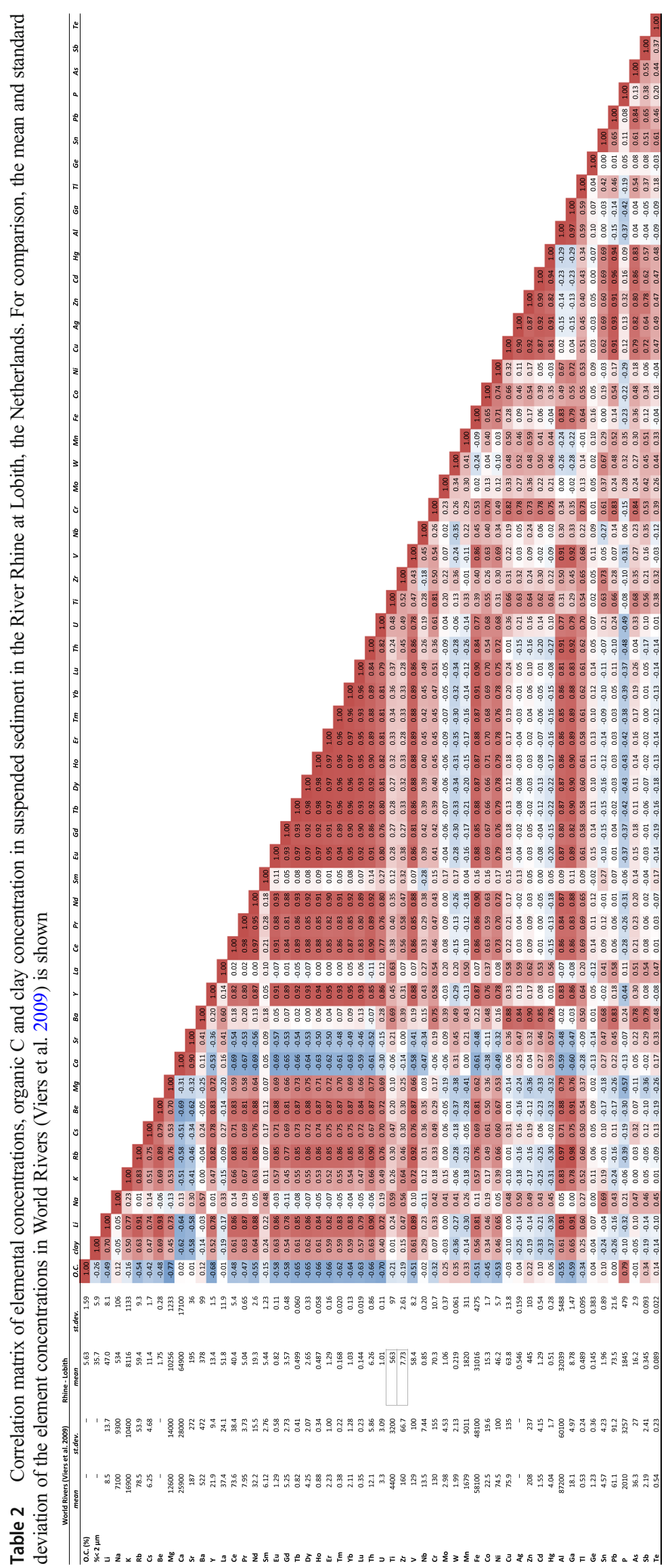


moderately to strongly positively correlated with clay content and moderately to strongly negatively correlated with organic $\mathrm{C}$ content. Furthermore, they are moderately to strongly negatively correlated to $\mathrm{Ca}$ and $\mathrm{Sr}$. A second groups of elements is characterised by a similar, but weaker correlation to clay and organic $\mathrm{C}$ content $(\mathrm{Na}, \mathrm{Ba}, \mathrm{La}, \mathrm{Sm}, \mathrm{Ti}, \mathrm{Zr}, \mathrm{Nb}$ and $\mathrm{Cr}$ ). A third group consists of the elements $\mathrm{Mo}, \mathrm{W}, \mathrm{Mn}, \mathrm{Cu}, \mathrm{Ag}, \mathrm{Zn}, \mathrm{Cd}$, $\mathrm{Hg}, \mathrm{Sn}, \mathrm{Pb}, \mathrm{As}, \mathrm{Sb} \mathrm{Te}$, which are usually associated with pollution. These elements are generally weakly negatively correlated with the clay content of the suspended sediment. The fourth group, which consists of the mutually strongly correlated elements $\mathrm{Ca}$ and $\mathrm{Sr}$, which are, in turn, moderately negatively correlated with clay content and the above group of elements linked to clay minerals. P forms a fifth group characterised by a strong positive correlation with organic $\mathrm{C}$.

\subsection{Relation with discharge}

Table 3 lists the rating curve parameters and the coefficient of determination $\left(R^{2}\right)$, standard error and the $p$-value of the regression between the log-transformed concentration and log-transformed discharge. Figure 3 depicts the concentration-discharge relations including the fitted rating curves, for the elements that show a significant positive relationship (i.e. a positive value of $\beta$ that significantly deviates from zero at a significance level of 0.05 ) (Fig. 3a), a significant negative relationship (Fig. 3b), and a non-significant relationship with discharge (Fig. 3c). The elements that show a positive value of $\beta$ belong in most cases to above group of elements that are traditionally linked to clay minerals. The clay content of suspended sediment also shows a positive value of $\beta$ (i.e. clay content increases with discharge), whereas the organic matter content shows a negative value of $\beta$. The elements that show a negative value of $\beta$ belong in most cases to above group of elements that are traditionally associated with pollution.

In general, the residuals of the relation between the elemental concentration and discharge (see Fig. 3) display a seasonal pattern with positive residuals (i.e. predicted concentrations using the power-law rating curve greater than the observed concentrations) during spring and summer months (April-September) and negative residuals during autumn and winter (October-March). Especially for group of the elements that are linked to clay minerals, the residuals are negatively correlated to clay $(<2 \mu \mathrm{m})$ content (correlation coefficients generally between -0.25 and -0.5 ) and positively correlated to organic $\mathrm{C}$ content (correlation coefficients generally between 0.4 and 0.6 ). The rating curve residuals of the $\mathrm{Ca}$ and $\mathrm{Sr}$ show a different seasonal pattern and are generally positive between January and April and negative during the rest of the year.
Table 3 Rating curve parameters $\mathrm{a}$ and $\mathrm{b}$ and the coefficient of determination $\left(R^{2}\right)$, standard error (S.E.) and the $p$-value of the regression between the log-transformed concentration and log-transformed discharge

\begin{tabular}{|c|c|c|c|c|c|}
\hline Element & $\mathrm{a}$ & $\mathrm{b}$ & $R^{2}$ & S.E. & $p$-value \\
\hline $\mathrm{Li}$ & 8.6 & 0.224 & 0.316 & 0.062 & $\ll 0.001$ \\
\hline $\mathrm{Na}$ & 2809 & -0.220 & 0.254 & 0.071 & $\ll 0.001$ \\
\hline K & 2866 & 0.137 & 0.193 & 0.053 & $\ll 0.001$ \\
\hline $\mathrm{Rb}$ & 13.2 & 0.198 & 0.288 & 0.059 & $\ll 0.001$ \\
\hline Cs & 6.45 & 0.075 & 0.045 & 0.065 & 0.008 \\
\hline $\mathrm{Be}$ & 0.32 & 0.222 & 0.343 & 0.058 & $\ll 0.001$ \\
\hline $\mathrm{Mg}$ & 3089 & 0.158 & 0.285 & 0.048 & $\ll 0.001$ \\
\hline $\mathrm{Ca}$ & 1034640 & -0.367 & 0.373 & 0.090 & $\ll 0.001$ \\
\hline $\mathrm{Sr}$ & 1898 & -0.302 & 0.496 & 0.058 & $\ll 0.001$ \\
\hline $\mathrm{Ba}$ & 4682 & -0.333 & 0.328 & 0.091 & $\ll 0.001$ \\
\hline Y & 6.23 & 0.101 & 0.120 & 0.052 & $\ll 0.001$ \\
\hline $\mathrm{La}$ & 658 & -0.337 & 0.389 & 0.080 & $\ll 0.001$ \\
\hline $\mathrm{Ce}$ & 13.7 & 0.142 & 0.201 & 0.054 & $\ll 0.001$ \\
\hline $\operatorname{Pr}$ & 1.92 & 0.127 & 0.173 & 0.053 & $\ll 0.001$ \\
\hline $\mathrm{Nd}$ & 5.60 & 0.163 & 0.245 & 0.054 & $\ll 0.001$ \\
\hline $\mathrm{Sm}$ & 5.66 & -0.005 & 0.000 & 0.094 & 0.896 \\
\hline $\mathrm{Eu}$ & 0.23 & 0.168 & 0.263 & 0.053 & $\ll 0.001$ \\
\hline $\mathrm{Gd}$ & 1.07 & 0.159 & 0.220 & 0.057 & $\ll 0.001$ \\
\hline $\mathrm{Tb}$ & 0.15 & 0.159 & 0.275 & 0.049 & $\ll 0.001$ \\
\hline Dy & 0.77 & 0.164 & 0.279 & 0.050 & $\ll 0.001$ \\
\hline Но & 0.16 & 0.147 & 0.236 & 0.050 & $\ll 0.001$ \\
\hline Er & 0.42 & 0.147 & 0.226 & 0.052 & $\ll 0.001$ \\
\hline $\mathrm{Tm}$ & 0.06 & 0.142 & 0.223 & 0.050 & $\ll 0.001$ \\
\hline $\mathrm{Yb}$ & 0.34 & 0.145 & 0.217 & 0.053 & $\ll 0.001$ \\
\hline $\mathrm{Lu}$ & 0.05 & 0.136 & 0.172 & 0.057 & $\ll 0.001$ \\
\hline Th & 1.50 & 0.188 & 0.318 & 0.052 & $\ll 0.001$ \\
\hline U & 0.53 & 0.086 & 0.100 & 0.049 & $\ll 0.001$ \\
\hline $\mathrm{Ti}$ & 1885 & -0.160 & 0.158 & 0.070 & $\ll 0.001$ \\
\hline $\mathrm{Zr}$ & 8.2 & -0.008 & 0.000 & 0.145 & 0.904 \\
\hline V & 21.7 & 0.130 & 0.153 & 0.058 & $\ll 0.001$ \\
\hline $\mathrm{Nb}$ & 0.64 & 0.038 & 0.005 & 0.099 & 0.376 \\
\hline $\mathrm{Cr}$ & 157 & -0.106 & 0.099 & 0.061 & $\ll 0.001$ \\
\hline Mo & 3.09 & -0.142 & 0.072 & 0.097 & 0.001 \\
\hline W & 1.35 & -0.241 & 0.133 & 0.117 & $\ll 0.001$ \\
\hline $\mathrm{Mn}$ & 6345 & -0.165 & 0.182 & 0.066 & $\ll 0.001$ \\
\hline $\mathrm{Fe}$ & 12231 & 0.123 & 0.137 & 0.058 & $\ll 0.001$ \\
\hline Co & 13.5 & 0.017 & 0.003 & 0.054 & 0.471 \\
\hline $\mathrm{Ni}$ & 21.1 & 0.103 & 0.116 & 0.054 & $\ll 0.001$ \\
\hline $\mathrm{Cu}$ & 458 & -0.261 & 0.295 & 0.077 & $\ll 0.001$ \\
\hline $\mathrm{Ag}$ & 14.0 & -0.431 & 0.454 & 0.090 & $\ll 0.001$ \\
\hline $\mathrm{Zn}$ & 6265 & -0.351 & 0.425 & 0.077 & $\ll 0.001$ \\
\hline $\mathrm{Cd}$ & 149 & -0.632 & 0.523 & 0.114 & $\ll 0.001$ \\
\hline $\mathrm{Hg}$ & 506 & -0.923 & 0.725 & 0.108 & $\ll 0.001$ \\
\hline $\mathrm{Al}$ & 5847 & 0.224 & 0.297 & 0.065 & $\ll 0.001$ \\
\hline $\mathrm{Ga}$ & 1.60 & 0.224 & 0.303 & 0.065 & $\ll 0.001$ \\
\hline $\mathrm{Tl}$ & 0.40 & 0.025 & 0.004 & 0.077 & 0.445 \\
\hline $\mathrm{Ge}$ & 0.06 & 0.088 & 0.004 & 0.255 & 0.422 \\
\hline Sn & 124 & -0.552 & 0.310 & 0.156 & $\ll 0.001$ \\
\hline $\mathrm{Pb}$ & 1638 & -0.412 & 0.444 & 0.087 & $\ll 0.001$ \\
\hline $\mathrm{P}$ & 7172 & -0.179 & 0.064 & 0.130 & 0.002 \\
\hline As & 78.2 & -0.208 & 0.297 & 0.061 & $\ll 0.001$ \\
\hline $\mathrm{Sb}$ & 2.98 & -0.286 & 0.239 & 0.097 & $\ll 0.001$ \\
\hline $\mathrm{Te}$ & 0.63 & -0.259 & 0.204 & 0.097 & $\ll 0.001$ \\
\hline
\end{tabular}

\subsection{Principal component analysis}

Table 4 summarises the results of the principal component analyses on the untransformed element concentrations (Table 4a), the Al-normalised concentrations (Table 4b) and the organic C-normalised concentrations (Table 4c). The PCA 

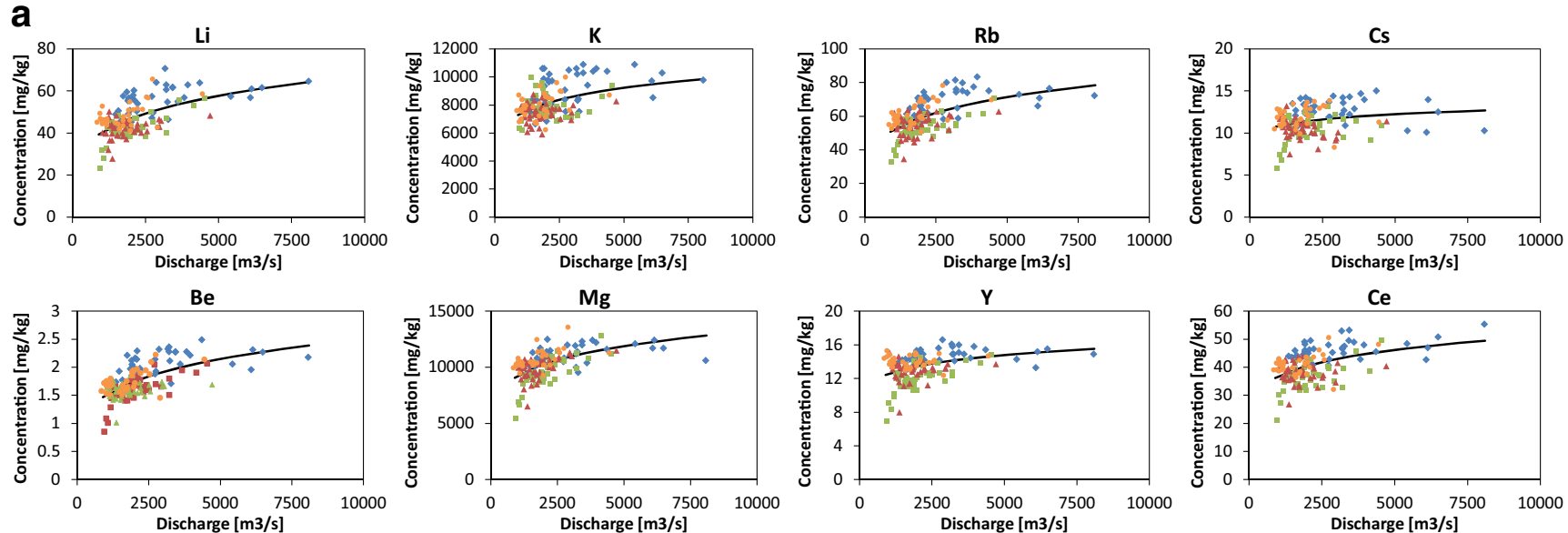

Ce

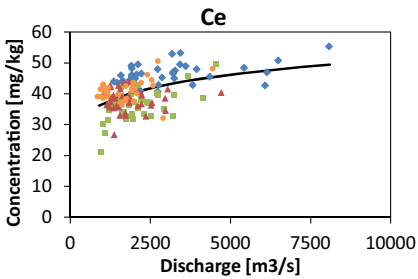

$\operatorname{Pr}$

$\mathrm{Nd}$
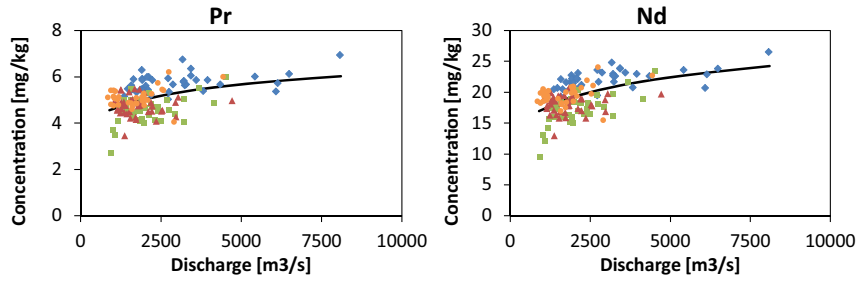

Eu

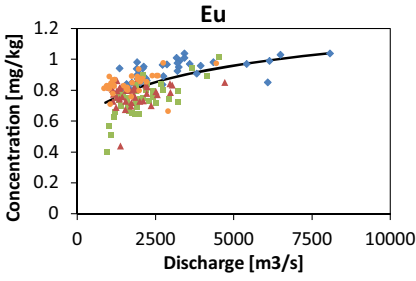

Gd

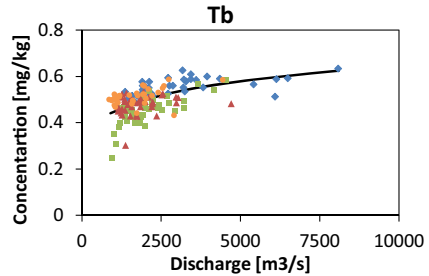

Dy

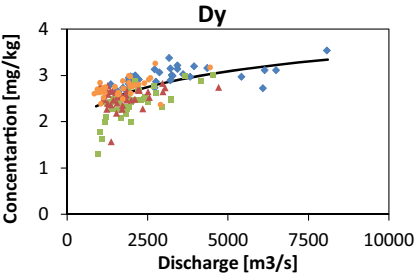

Ho
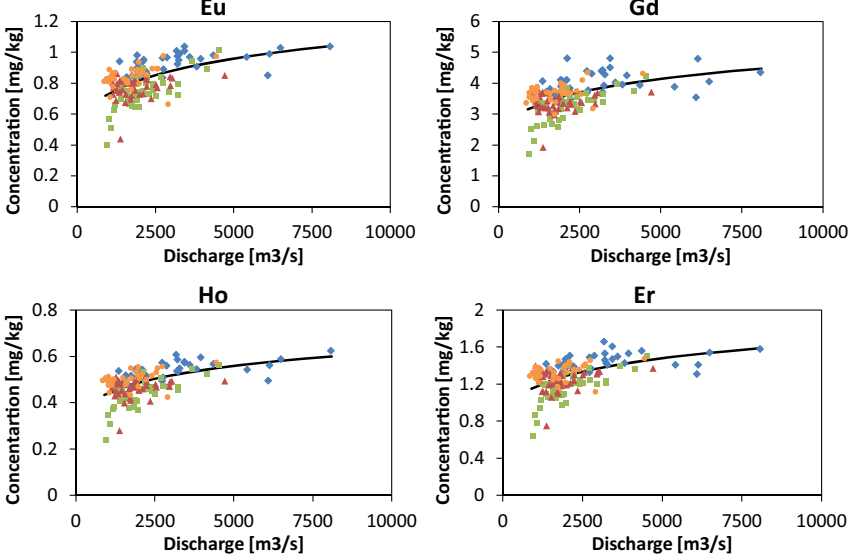

Er

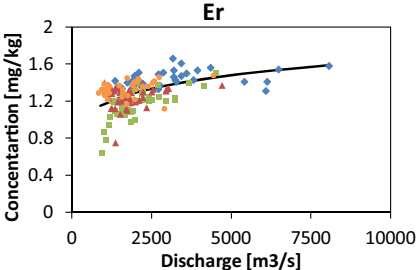

Tm

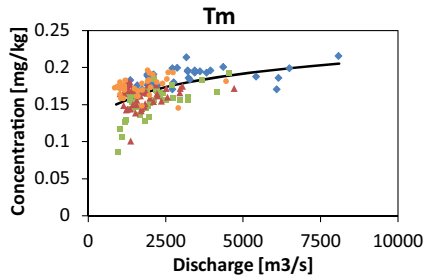

Yb

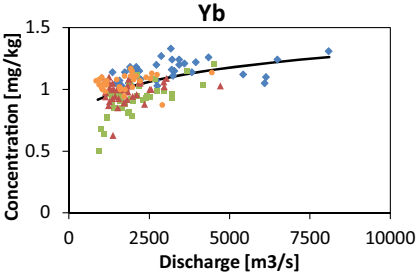

Lu

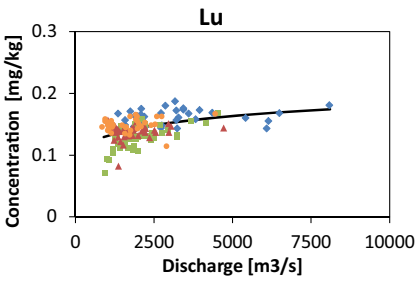

Th
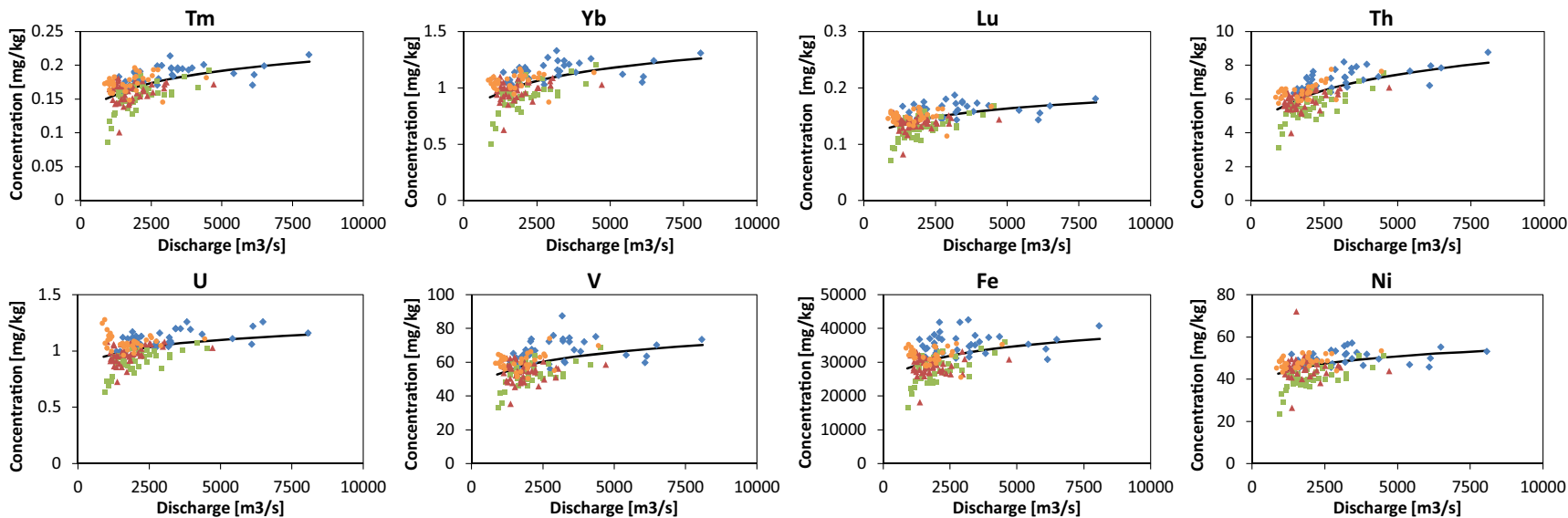

Al
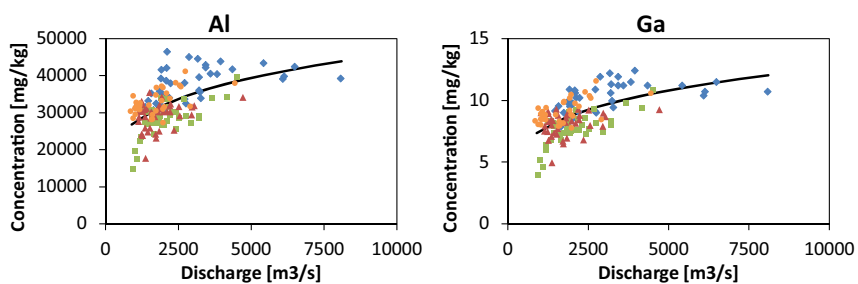

Fig. 3 a Concentration-discharge relations of elements showing a significant positive relation with discharge. The different colours represent the seasons during which the samples were collected: winter (January-March), spring (April-June), summer (July-September) and autumn (October-December). b Concentration-discharge relations of elements showing a significant negative relation with discharge. The different colours represent the seasons during which the samples were September) and autumn (October-December). c Concentration-discharge relations of elements showing neither a significant positive relation nor a significant negative relation with discharge. The different colours represent the seasons during which the samples were collected: winter (January-March), spring (April-June), summer (July-September) and autumn (October-December) 

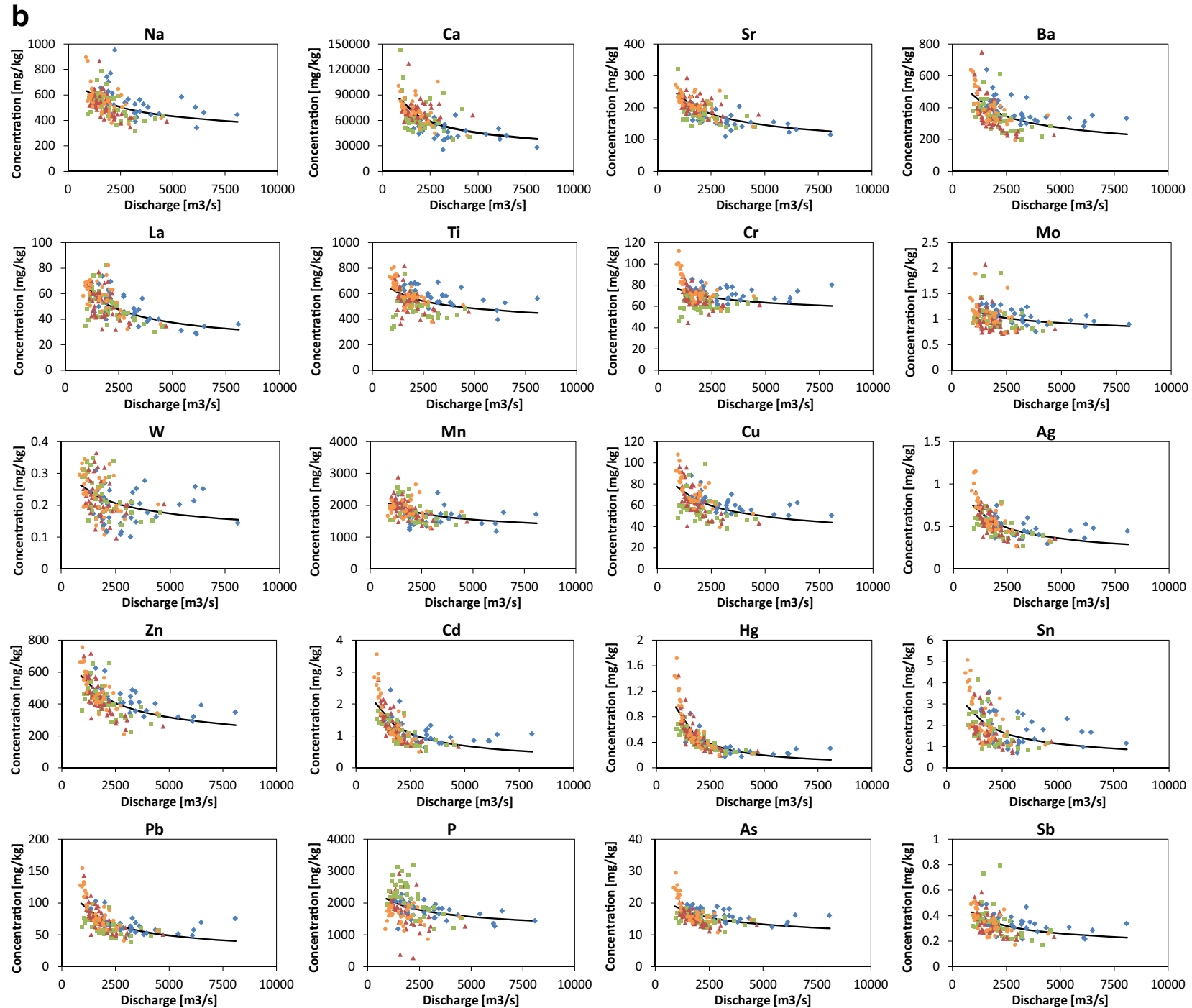

$\mathrm{Sb}$
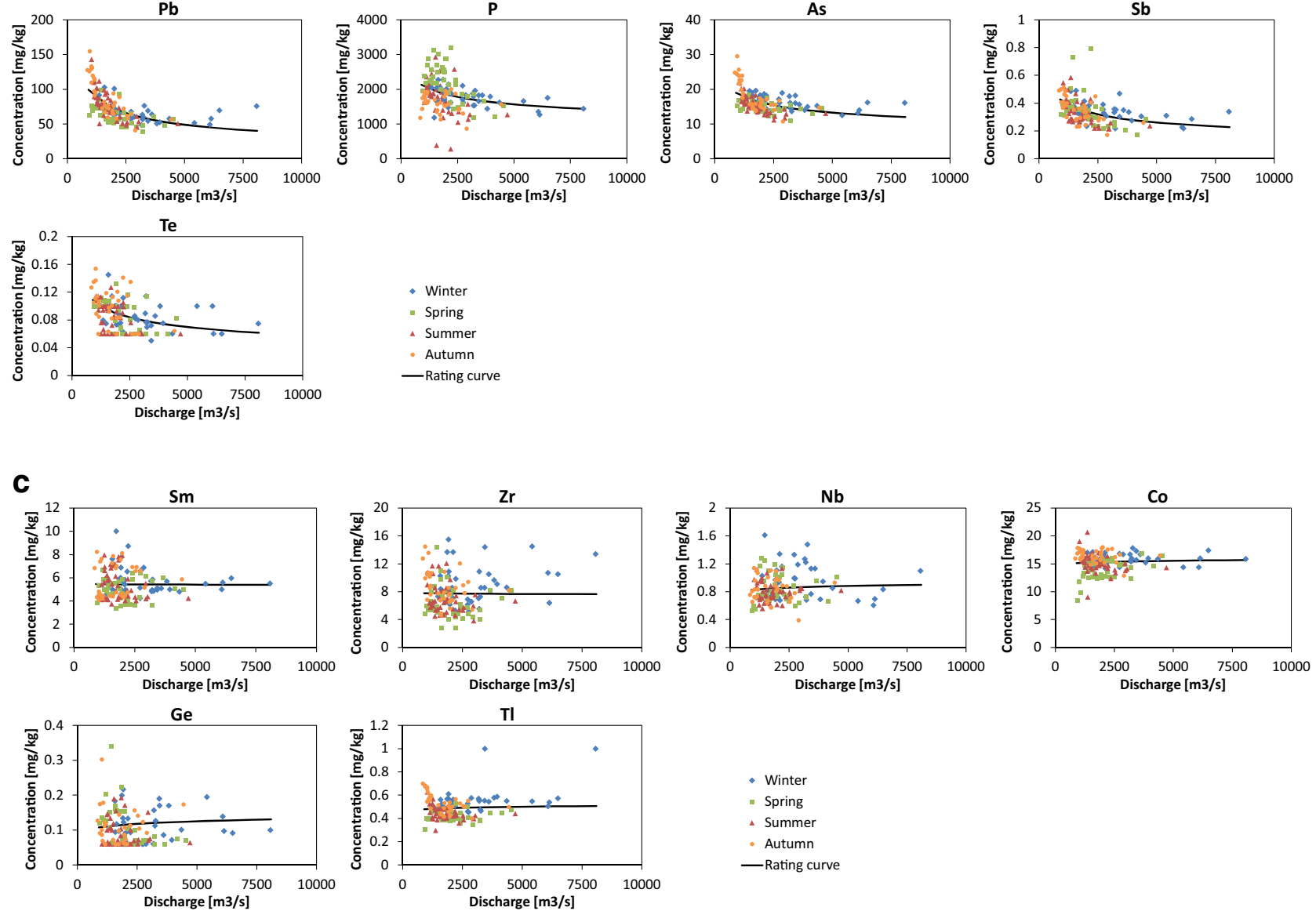

Fig. 3 (continued)

Springer 


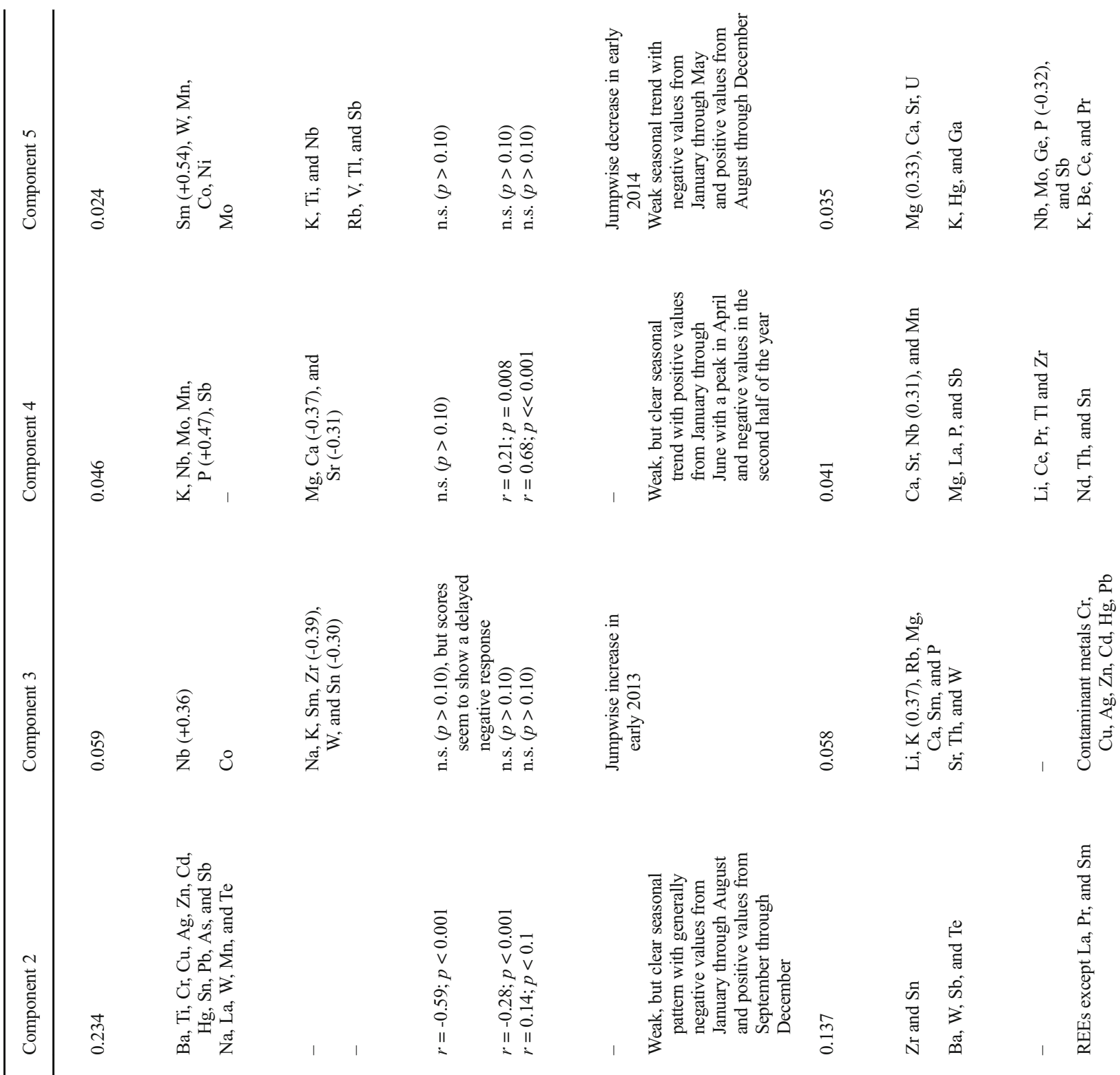

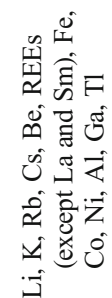

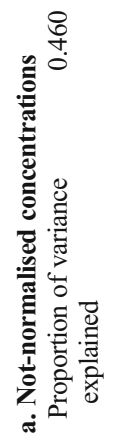

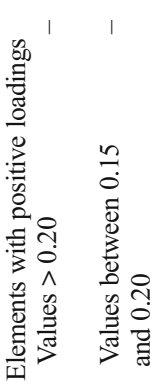

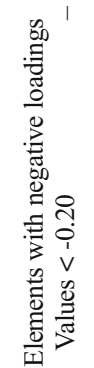

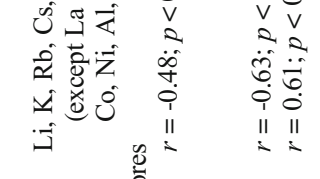
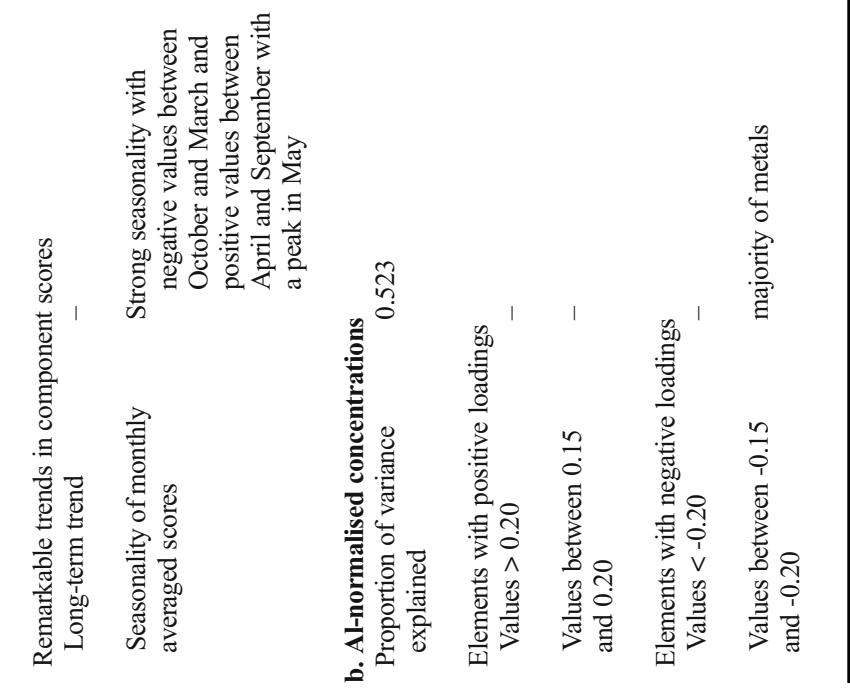

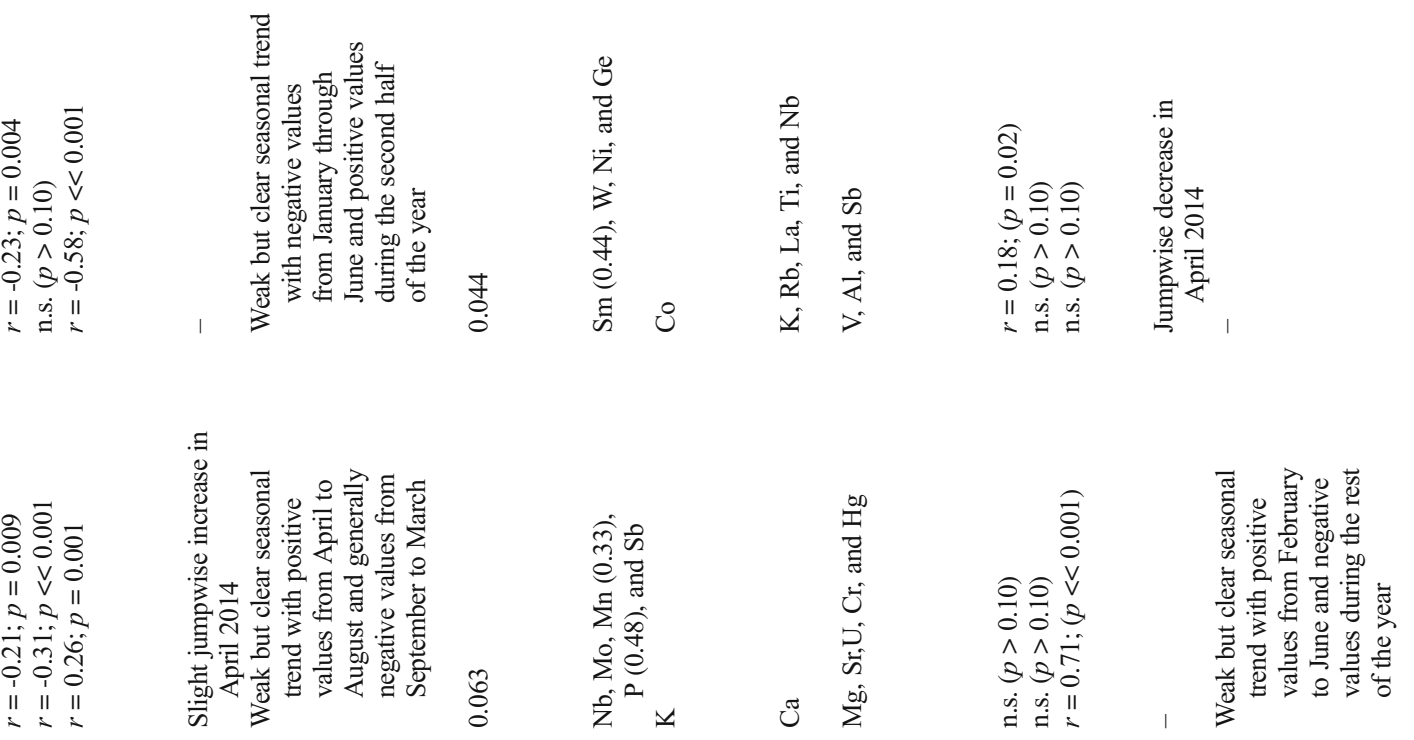

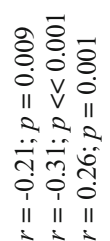

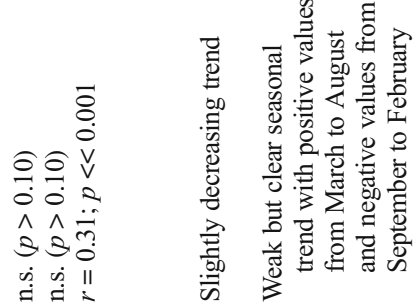
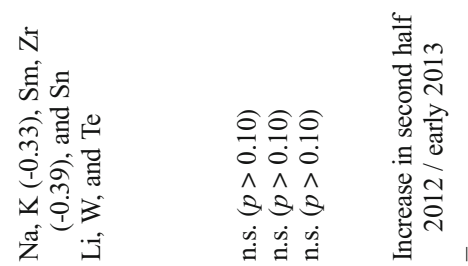

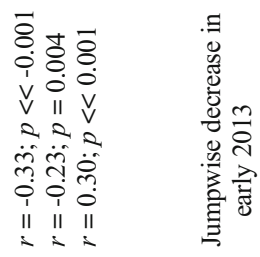

荌 8

오욜

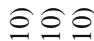

i०

$3 \hat{3}$

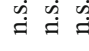

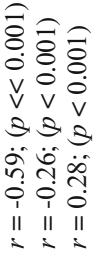

훙ㅎㅁㅇㅎㅇ
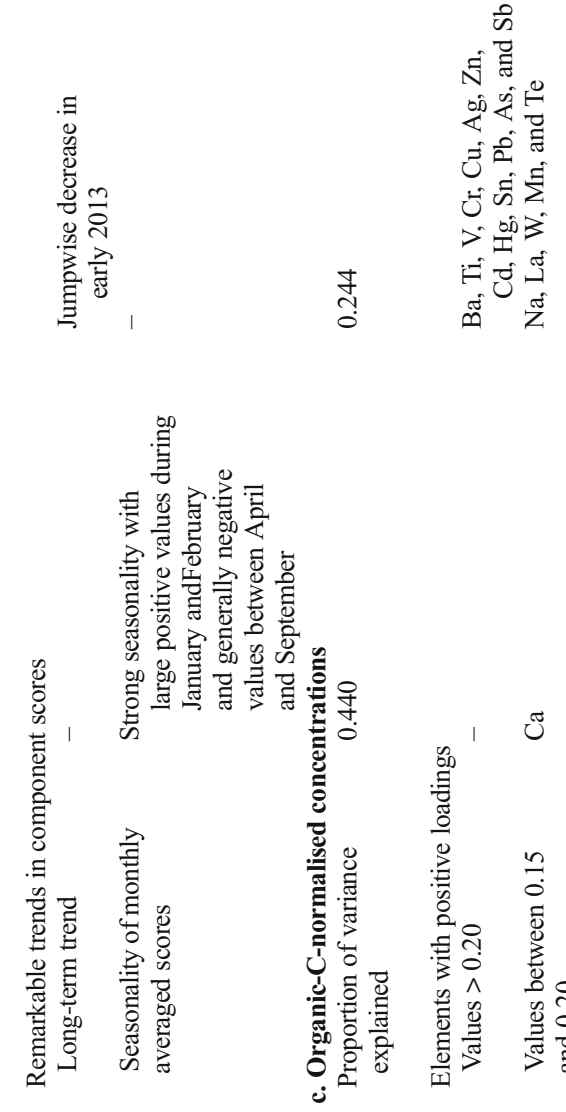

롱명

芴丞

㲅㐫

कीज्ञ

वे है

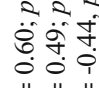

पII II II

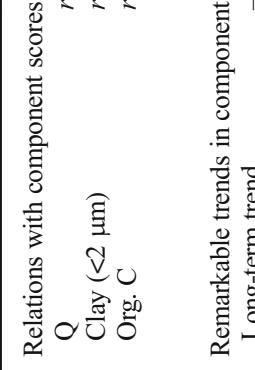

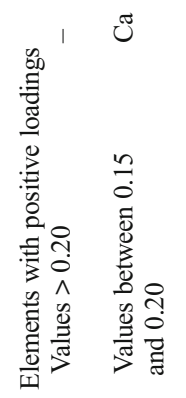
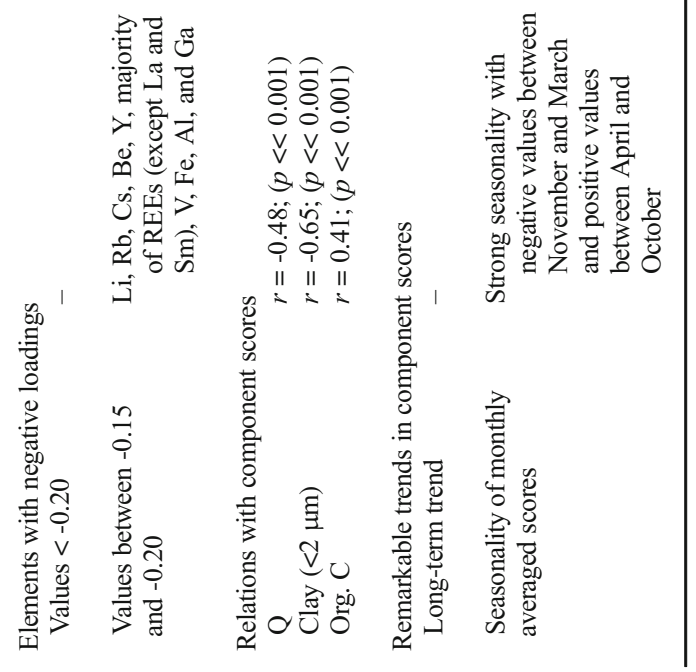
of the untransformed concentrations yields five components that explain $82.4 \%$ of the total variance in the dataset. The remaining components explain less than $2.5 \%$ of the total variation each; the sixth component ( $2.4 \%$ explained variance) is mainly determined by La (loading 0.47). The PCA of the Al-normalised concentrations yields five components that explain together $79.4 \%$ and the PCA of organic C-normalised element concentrations five components that explain $81.7 \%$ of the total variance in the respective data sets.

The PCA results show a consistent pattern of components representing similar behaviour with groups of elements and different behaviours between these groups. The similar components are indicated by different colour shadings in Table 4 and are described and explained in further details below.

The first component for all PCA analyses, which explains between 44 and $53 \%$ of the total variance in the data sets, represents the variation in the concentrations of especially REEs (except La and Sm) and other metals that are significantly positively related to discharge and clay content and significantly negatively to organic matter content. The concentrations of these metals show a strong seasonal trend with lower concentrations during summer than during winter. The Al-normalised concentrations of these metals show opposite relations with discharge, clay content, organic matter content, and season.

A second component (third component for the Alnormalised concentrations) represent the variation in the contaminant metals $\mathrm{Cr}, \mathrm{Cu}, \mathrm{Ag}, \mathrm{Zn}, \mathrm{Cd}, \mathrm{Hg}, \mathrm{Sn}$ and $\mathrm{Pb}$. Other elements that have relatively high loadings on this factor include $\mathrm{Ba}, \mathrm{La}, \mathrm{Ti}, \mathrm{Sb}$, and As. This component explains about $24 \%$ of the total variance in the data sets for the notnormalised and organic-C-normalised concentrations, but only about $6 \%$ for the total variance in the data set for Alnormalised concentrations. The component scores for the not-normalised and the Al-normalised concentrations show a weak seasonal trend whereas the scores for the organic-Cnormalised do not show any seasonal variation.

The third component (second component for the Alnormalised concentrations) represents the variation of the concentrations of $\mathrm{Zr}, \mathrm{Sn}, \mathrm{Nb}$ and $\mathrm{Co}$ in particular. This third component explains about $5.5 \%$ of the total variance in the data sets for the not-normalised and organic-C-normalised concentrations and about $14 \%$ for the total variance in the data set for Al-normalised concentrations. The component scores for the not-normalised and organic C-normalised concentrations are not statistically significantly related to discharge, clay and organic matter. However, the component scores of the Alnormalised concentrations are significantly related to these variables. Furthermore, this component is characterised by a 'jumpwise' shift in early 2013, which represents an increase in $\mathrm{Nb}$ concentrations and a decrease in $\mathrm{Zr}$ and, to a lesser extent, Sn concentrations.
The fourth component (fifth component for the Alnormalised concentrations) represents a large part of the variation in $\mathrm{P}$ concentrations and explains between 3.5 and $6.3 \%$ of the total variance in the data sets. The component scores are relatively strongly related to the organic $\mathrm{C}$ content of the suspended sediment and show a weak but clear seasonal trend with high values from January through June, with a maximum in April, and relatively low values during the second half of the year.

The remaining fifth component for the not-normalised and the organic-C-normalised concentrations represents the variations in $\mathrm{Sm}, \mathrm{W}, \mathrm{Ni}, \mathrm{Co}, \mathrm{K}, \mathrm{Ti}, \mathrm{Rb}, \mathrm{Nb}, \mathrm{V}$ and $\mathrm{Nb}$ concentrations. This component explains only $2.4 \%$ and $4.4 \%$ of the total variance in the respective data sets. The component scores are characterised but a jump-wise decrease in early 2014. Although scores of the fourth component for the Alnormalised concentrations are also characterised by a shift in early 2014, the elements contributing to this fourth component are different from the elements contributing to the fifth component for the other data sets.

\section{Discussion}

In general, the average elemental concentrations in Rhine suspended sediment are generally well within the range reported for the world rivers (Viers et al. 2009), although they are slightly lower than the average concentrations in the world rivers. Exceptions are $\mathrm{Zn}$ and $\mathrm{Pb}$, which have higher average concentrations in the Rhine River than in the world rivers, which may likely be attributed to legacy and current anthropogenic pollution in the Rhine catchment (Middelkoop 2000; Vijver et al. 2008). Ti, $\mathrm{Zr}$, and $\mathrm{Nb}$ are also exceptions, but these elements have substantially lower concentrations in the Rhine River than in the world rivers. The precise reason for this deviation is unknown, but it might be due to the difference in analytical method and the digestion procedure in particular. The Rhine suspended sediment samples are digested using nitric acid, which may not dissolve the total amount of these elements in the sample. The digestion procedures in the database of the chemical composition of suspended sediments in the world rivers is not reported by Viers et al. (2009).

The results of our data analyses on the elemental concentrations in suspended sediment shows a consistent grouping of elements that display contrasting temporal variation reflected in different seasonal or long-term variations or different responses to increased discharge. This contrasting temporal behaviour becomes manifest in the results from the PCA. The first component from the PCA represents the variation in the concentrations of elements that are generally associated with fine-grained inorganic mineral fraction of suspended sediment (Luoma and Rainbow 2008; Van der Perk 2013). This becomes manifest in a moderate-to-strong positive correlation 
between these elements and clay content (particle size $<2 \mu \mathrm{m}$ ) and a moderate-to-strong negative correlation with organic $\mathrm{C}$ content. Note that the correlation of the component scores with clay and organic matter content have the opposite sign. The elements represented by this first component show a positive relation between their concentration in suspended sediment and discharge, which may be attributed to an increased supply of fine-grained clastic matter to and mobilisation in the river channel network during periods of increased discharge. The elements thus likely originate from diffuse, primarily geogenic sources. The negative correlation of the element concentrations with organic $\mathrm{C}$ and the seasonal variation of the residuals of the concentration-discharge relation is probably caused by primary production of organic C, which dilutes the inorganic fraction and associated elements in the suspended sediment (Winkels et al. 1998; Hamers et al. 2015). Assuming the organic matter content of suspended sediment is twice the organic $\mathrm{C}$ content, the dilution factor due to variations in organic $\mathrm{C}$ varies between about 1.09 and 1.15. Moreover, the concentrations of clay-associated elements are negatively correlated to the $\mathrm{Ca}$ and $\mathrm{Sr}$ concentrations, which may be explained by dilution of the clay-associated element concentrations by calcite precipitation. This process may contribute to the above seasonality in concentrations and residuals.

Notably, normalisation of the element concentrations to $\mathrm{Al}$ or organic $\mathrm{C}$ - and the subsequent $\mathrm{Z}$-normalisation of the $\mathrm{Al}$ and organic $\mathrm{C}$ normalised concentrations - does not result in a substantial decrease in the proportion explained by the first component associated with variations in clay-associated elements. Apparently, the variations in $\mathrm{Al}$ and organic $\mathrm{C}$ do not fully represent the variation in metal concentrations due to the content of clay minerals and the clay effect remains persistent in the normalised concentrations.

The second component for the not-normalised concentrations represents the variation in the concentrations of contaminant elements including $\mathrm{Cr}, \mathrm{Cu}, \mathrm{Zn}, \mathrm{Cd}, \mathrm{Hg}$ and $\mathrm{Pb}$, which are adsorbed to both organic and inorganic fractions of suspended sediment (Luoma and Rainbow 2008; Kulaksiz and Bau 2011; Van der Perk 2013). These contaminant elements are largely derived from point source discharges into the river network (Vink and Behrendt 2002). Their concentrations generally show a negative relation with discharge, a weak negative relation to clay content, and a weak positive relation to organic $\mathrm{C}$ content. This opposite response compared with the above first group of elements may also be attributed to inputs of relatively uncontaminated clastic material during periods of increased discharge. These inputs dilute the contaminant concentrations in suspended sediments. The fact that the relation to organic $\mathrm{C}$ is only weak is likely the result of variation in the organic $\mathrm{C}$ content of suspended sediments due to internal primary production.
The third component is characterised by a jump-wise shift in concentrations in early 2013 indicating a breakthrough of sediment relatively rich in $\mathrm{Nb}$ and relatively poor in $\mathrm{Na}, \mathrm{K}, \mathrm{Sm}$ and $\mathrm{Zr}$. The origin of this breakthrough event is more difficult to interpret. It could be the result of a sudden input of sediment due to a past hydrologic event or human intervention in the river system, for example the recurrent addition of sediment in the upstream German reach of the Rhine River to counteract channel incision (Frings et al. 2014a, b). Although the added sediment consists of coarse material, abrasion of this sediment could lead to a shift in the elemental composition of the fine fraction that is transported in suspension. To test the above hypothesis requires information on the geochemical composition of the artificially added sediment and its derivatives.

The fourth component for the not-normalised concentrations is dominated by the variation in $\mathrm{P}$ concentrations and is characterised by a strong positive correlation with organic $\mathrm{C}$ content and a weak but significant positive correlation with clay content. The seasonal pattern of the PCA scores with high values during spring together with the absence of a significant correlation with discharge suggests that this component represents the inputs of P-rich terrestrial organic matter through soil erosion processes rather than $\mathrm{P}$ inputs from sewage treatment plants or sewage overflows. During spring, the supply of sediments and particulate $\mathrm{P}$ to the River Rhine reaches its maximum value because of the high soil moisture levels and bare fields (Van Dijk 2001; Schulz and Bischoff 2008). The concomitant inputs of inorganic and organic soil particles may explain the positive correlation with clay content. Furthermore, the negative loadings of $\mathrm{Ca}, \mathrm{Mg}$ and $\mathrm{Sr}$ on the fourth component indicate that during winter and spring, the supply of the P-rich terrestrial organic matter coincides with a decreased contribution of sediments from the Swiss part of the Rhine basin, where the concentrations of these elements in stream sediment are higher than in the German part of the basin. This suggests that the terrestrial organic matter is mainly derived from the German part of the catchment. Calcite dissolution during winter and precipitation during summer may also contribute the seasonal pattern of the PCA scores (Van der Weijden and Middelburg 1989), although the peak and trough of the PCA scores are three months later than the expected maxima of calcite dissolution and precipitation.

This study can be seen as an update of the study by Van der Weijden and Middelburg (1989), who performed a similar multivariate analysis on the geochemical composition of suspended sediment in the Rhine at Lobith for the period between 1975 and 1981. However, their data set was less extensive in terms of the number of elements analysed. In their 1980s study, Van der Weijden and Middelburg (1989) distinguished four factors which together explained $75 \%$ of the total variation: (1) heavy metals $(47.0 \%),(2)$ clays (11.5\%), (3) calcium carbonate (8.8\%) and (4) manganese oxides (7.9\%). The first factor identified in the 1980s study 
is comparable with our second component and can mainly be attributed to variation in sediment composition due to anthropogenic inputs, i.e. pollution. This factor was explained by the dominant decreasing trend in pollution in the late 1970s and early 1980s. Nowadays, such trend is absent and the variation in contaminant metals are primarily due to discharge variations and related variations of inputs of relatively uncontaminated sediment. The second factor in the 1980s study is comparable with our first component. The fact that our first and second factor are in reversed order in comparison with the first two factors identified in the 1980s study can probably be largely attributed to the fact that during the 1970s, the contaminant concentrations in suspended sediment were subject to larger variations associated to the aforementioned pollution trend and a possibly stronger negative response of contaminant concentrations to discharge events. Furthermore, a larger number of elements associated with clay minerals and less affected by anthropogenic pollution were taken in to consideration in our analysis compared with the 1980 study. This could also contribute to the reversal of the order of the factors. The third (calcium carbonate) and fourth (manganese) factors identified in the 1980 study were not found in this study as separate principal components. The calcium carbonate and manganese factors were subject to strong seasonality and likely driven by eutrophication processes. The reason that these factors did not become manifest in our PCA may be attributed to the strong decline in eutrophication in the River Rhine since the 1980s (Hartmann et al. 2007). Thus, comparison of our results with the precursor study by Van der Weijden and Middelburg (1989) demonstrates that anthropogenic pollution strongly affects the compositional dynamics of suspended sediment in rivers. Although the contamination levels in the Rhine River have been substantially reduced since the 1970 s and 1989s (Hartmann et al. 2007; Van der Perk 2013), the pollution factor (second component for the not-normalised concentrations) still accounts for a considerable proportion of the variation in suspended sediment composition.

Data presented by Le Meur et al. (2016) for various measurement locations in the French Mosel River (a major tributary of the Rhine River in France and Germany) and its tributaries generally show a similar response of element concentrations to discharge variations. The element concentrations in suspended sediment in the Mosel catchment show generally positive responses for REEs and a negative response for the contaminant metals $\mathrm{Cu}, \mathrm{Pb}, \mathrm{Cd}$ and $\mathrm{Zn}$ (Le Meur et al. 2016). Negative responses of $\mathrm{Cu}$ concentrations in the Rhine and Meuse Rivers to discharge were also reported by Hamers et al. (2015). In contrast to our results, Ba in the Mosel catchment shows generally a positive response to discharge (Le Meur et al. 2016). The negative response of the Ba concentrations in Rhine suspended sediment at the Lobith monitoring station suggests that the Ba concentrations are primarily controlled by anthropogenic inputs, whereas the $\mathrm{Ba}$ concentrations in the Mosel catchment are likely largely controlled by inputs from geogenic sources. The reported Ba concentrations in suspended matter in the Mosel catchment is on average higher (Le Meur et al. 2016) than that at Lobith (this study). This can be attributed to the higher Ba concentrations in soils and stream sediments in the Mosel catchment than in the downstream parts of the Rhine catchment (Salminen et al. 2005). Furthermore, In the Mosel catchment, Cr show a shift from the more geogenically controlled, positive response to discharge in the upstream parts of the catchment to an anthropogenically controlled, negative response more downstream (Le Meur et al. 2016). This is in agreement with the negative response of $\mathrm{Cr}$ to discharge found in this study.

The deviating behaviour of La and Sm in the Rhine suspended sediment compared with the other REEs, which becomes manifest in the correlation matrix (Fig. 2) and the relation with discharge (Fig. 3a-c), was also reported by Kulaksiz and Bau (2011). They identified the source of anthropogenic pollution of $\mathrm{La}$ and $\mathrm{Sm}$ to be an industrial discharge of waste water just north of Worms in Germany (approximately $410 \mathrm{~km}$ upstream from the Lobith monitoring station). The anthropogenic Gd anomaly observed by Kulaksiz and Bau (2011) was not observed in our study because anthropogenic Gd is only present in dissolved phase (Klaver et al. 2014).

The effect of dilution of anthropogenically contaminated suspended sediment by sediment inputs from land surface erosion was also found by Ollivier et al. (2011) for the Rhône River in France and by Ma et al. (2015) for the Daliao River and Estuary in China. Ma et al. (2015) reported concentrations of contaminant metals in suspended sediment to be on average 2-3 times higher during the dry season than during the wet season. The seasonal variation in contaminant concentrations in suspended sediment due to interannually produced organic matter due to algal blooms was also reported by Hamers et al. (2015) for metals and organic pollutants. Previously, this seasonality in element concentrations on suspended sediment had been observed in the Scheldt estuary in the southwestern part of the Netherlands (Zwolsman and Van Eck 1999) and in freshwater lakes that are fed by the downstream distributaries of the Rhine River (Van de Meent et al. 1985; Koelmans 1998; Winkels et al. 1998).

The concentration-discharge relationships derived in this study can be used to estimate a continuous time-series of sediment-associated element concentrations in the Rhine River analogous to the rating curve method to estimate suspended sediment concentrations (Ferguson 1986). The estimation of element concentrations may be improved by the seasonal variation in residuals of the concentration-discharge relationships taking into account. The resulting estimated element concentrations can subsequently be combined with measured or rating curve-estimated suspended sediment 
concentrations to obtain monthly, seasonal or annual sediment-associated element loads.

This study shows factors that do not directly relate to sediment source type or area (i.e. clay/organic C content and anthropogenic pollution) explain the majority, approximately $70 \%$, of the temporal variation in suspended sediment composition in the Rhine River. These factors should thus be omitted in identifying the sediment provenance, which therewith also eliminates many of the issues common in sediment fingerprinting studies, including effects of grain size, geochemical transformation and internal organic matter production (Koiter et al. 2013; Laceby et al. 2017; Smith and Karam Lennard 2018). The selection of sediment tracers and fingerprints should thus be based on the other components which may be associated with sediment source areas, but only explain a minor proportion of the total variation in suspended sediment composition. To identify the sediment source areas and to quantify the contribution of these source areas to the suspended sediment load, additional information is required about the geochemical composition of the top soils in the upstream river basin. The use of geochemical databases such as the FOREGS Geochemical Atlas of Europe (Salminen et al. 2005) as a source of such information seems promising, but further study is required to evaluate the value and limitations of these data for this purpose.

\section{Conclusions}

This study examined the temporal variation of suspended sediment composition at the Lobith monitoring station in the Rhine River in the Netherlands. The analysis of a comprehensive dataset for the period between 2011 and 2016 shows that the composition of suspended sediment is for a large part controlled by the clay content. The clay content is, in turn, controlled by inputs of clastic materials during hydrologic events and seasonality. This becomes manifested in increased concentrations of geogenic elements, including $\mathrm{Li}, \mathrm{K}, \mathrm{Rb}, \mathrm{Cs}$, Be, REEs (except La and Sm), Fe, Co, Ni, Al, Ga and Tl, during periods of high discharges and decreased concentrations during summer when the primary production of organic matter dilutes the element concentrations.

The sediment composition is also affected by anthropogenic pollution that is mainly derived from point source discharges. Prominent anthropogenic pollutants in the Rhine River include "traditional" heavy metals such as $\mathrm{Cr}, \mathrm{Cu}, \mathrm{Zn}$, $\mathrm{Cd}, \mathrm{Hg}$ and $\mathrm{Pb}$, but also $\mathrm{Na}, \mathrm{La}, \mathrm{W}$ and Te. These concentrations of these elements in suspended sediment decrease with increasing discharge due to dilution by the increased inputs of clastic material during hydrologic events. The direction of the relation between element concentrations and discharge thus reveals important information whether the elements are of anthropogenic or geogenic origin. Furthermore, the sediment composition is also controlled by sediment provenance, but only a minority of the temporal variation can be attributed to this factor. This factor reveals itself in deviant temporal patterns of the PCA scores, which are independent from seasonality and discharge. The precise cause of these patterns is not yet fully understood.

The multi-variate analysis of the elemental composition of suspended sediment in combination with information on discharge, clay content, and organic $\mathrm{C}$ content, has demonstrated to be useful distinguish between the different factors controlling the suspended sediment composition, which allowed us to unravel the geogenic and anthropogenic sources of the elements.

Acknowledgements We thank the Helpdesk Water team and Onno Epema of Rijkswaterstaat for their help with acquiring background information about the monitoring data. Furthermore, two anonymous reviewers and the submission editor are acknowledged for their comments that helped to improve the manuscript.

Open Access This article is licensed under a Creative Commons Attribution 4.0 International License, which permits use, sharing, adaptation, distribution and reproduction in any medium or format, as long as you give appropriate credit to the original author(s) and the source, provide a link to the Creative Commons licence, and indicate if changes were made. The images or other third party material in this article are included in the article's Creative Commons licence, unless indicated otherwise in a credit line to the material. If material is not included in the article's Creative Commons licence and your intended use is not permitted by statutory regulation or exceeds the permitted use, you will need to obtain permission directly from the copyright holder. To view a copy of this licence, visit http://creativecommons.org/licenses/by/4.0/.

\section{References}

Aitchison J (1986) The statistical analysis of compositional data. Chapman \& Hall, London

Asselman NEM (2000) Fitting and interpretation of sediment rating curves. J Hydrol 234:113-266

Belmont P, Gran KB, Schottler SP, Wilcock PR, Day SS, Jennings C, Lauer JW, Viparelli E, Willenbring JK, Engstrom DR, Parker G (2011) Large shirt in source of fine sediment in the Upper Mississippi river. Environ Sci Technol 45:8804-8810

Benson NU, Asuquo FE, Williams AB, Essien JP, Ekong CI, Akpabio O, Olajire AA (2016) Source evaluation and trace metal contamination in benthic sediments from equatorial ecosystems using multivariate statistical techniques. PLoS One 11:e0156485

Berner ZA, Bleeck-Schmidt S, Stüben D, Neumann T, Fuchs M, Lehmann M (2012) Floodplain deposits: a geochemical archive of flood history - a case study on the River Rhine, Germany. Appl Geochem 27:543-561

Carling (1983) Particulate dynamics, dissolved and total load, in two small basins, northern Pennines, UK. Hydrol Sci J 28:355-375

Colby BR (1956) Relationship of sediment discharge to streamflow. U.S. Dept. of the Interior, Geological Survey, Water Resources Division, Open-File Report 56-27, Washington, DC, USA

Collins AL, Walling DE, Leeks GJL (1997) Fingerprinting the origin of fluvial suspended sediment in larger river basins: combining 
assessment of spatial provenance and source type. Geogr Ann 79A:239-254

Collins AL, Pulley S, Foster IDL, Gellis A, Porto P, Horowitz AJ (2017) Sediment source fingerprinting as an aid to catchment management: a review of the current state of knowledge and a methodological decision-tree for end-users. J Environ Manag 194:86-108

Coynel A, Schäfer J, Blanc G, Bossy C (2007) Scenario of particulate trace metal and metalloid transport during a major flood event inferred from transient geochemical signals. Appl Geochem 22: $821-836$

Droppo IG, Jaskot C (1995) Impact of river transport characteristics on contaminant sampling error and design. Environ Sci Technol 29: $161-170$

Eisma D (1993) Suspended matter in the aquatic environment. Springer, Berlin Germany

Epema OJ, Zemmelink H (2017) Ananlyseboek milieu (in Dutch). Rijkswaterstaat CIV IGA-Laboratorium, Delft, The Netherlands https://www.helpdeskwater.nl/onderwerpen/monitoring/ gegevensinwinning/@176316/analyseboek-milieu/

Ferguson RI (1986) River loads underestimated by rating curves. Water Resour Res 22:74-76

Förstner U, Salomons W (1980) Trace metal analysis on polluted sediments. Part I: assessment of sources and intensities. Environ Technol 1:494-505

Frings RM, Döring R, Beckhausen C, Schüttrumpf H, Vollmer S (2014a) Fluvial budget of a modern, restrained river: the lower reach of the Rhine in Germany. Catena 122:91-102

Frings RM, Gehres N, Promny M, Middelkoop H, Schüttrumpf H, Vollmer S (2014b) Today's sediment budget of the Rhine River channel, focusing on the Upper Rhine Graben and Rhenish Massif. Geomorphology 204:573-587

Görgen K, Beersma J, Brahmer G, Buiteveld H, Carambia M, de Keizer O, Krahe P, Nilson E, Lammersen R, Perrin C, Volken D (2010) Assessment of climate change impacts on discharge in the Rhine River basin: results of the RheinBlick2050 Project. CHR report, I-23, Lelystad, The Netherlands

Haddadchi A, Ryder DS, Evrard O, Olley J (2013) Sediment fingerprinting in fluvial systems: review of tracers, sediment sources and mixing models. J Sediment Res 28:560-578

Hamers T, Kamstra JH, van Gils J, Kotte MC, van Hattum AGM (2015) The influence of extreme discharge conditions on the quality of suspended particulate matter in Rivers Meuse and Rhine (The Netherlands). Environ Res 143:241-255

Hartmann J, Jansen N, Kempe S, Dürr HH (2007) Geochemistry of the river Rhine and the Upper Danube: recent trends and lithological influence on baselines. J Environ Sci Sustain Soc 1:39-46

Hegnauer M, Beersma JJ, van den Boogaard HFP, Buishand TA, Passchier RH (2014) Generator of rainfall and discharge extremes (GRADE) for the Rhine and Meuse basins; final report of GRADE 2.0. Deltares Report 1209424-004, Delft, The Netherlands, http:// publications.deltares.n1/1209424_004_0018.pdf

Klaver G, Verheul M, Bakker I, Petelet-Giraud E, Négrel P (2014) Anthropogenic rare earth element in rivers: gadolinium and lanthanum. Partitioning between the dissolved and particulate phases in the Rhine River and spatial propagation through the Rhine-Meuse Delta (the Netherlands). Appl Geochem 47:186-197

Koelmans AA (1998) Geochemistry of suspended and settling solids in two freshwater lakes. Hydrobiologia 364:15-29

Koiter AJ, Owens PN, Petticrew EL, Lobb DA (2013) The behavioural characteristics of sediment properties and their implications for sediment fingerprinting as an approach for identifying sediment sources in river basins. Earth-Sci Rev 125:24-42

Kulaksız S, Bau M (2011) Rare earth elements in the Rhine River, Germany: first case of anthropogenic lanthanum as a dissolved microcontaminant in the hydrosphere. Environ Int 37:973-979
Laceby JP, Evrard O, Smith HG, Blake WH, Olley JM, Minella JPG, Owens PN (2017) The challenges and opportunities of addressing particle size effects in sediment source fingerprinting: a review. Earth-Sci Rev 169:85-103

Le Meur M, Montargès-Pelletier E, Bauer A, Gley R, Migot S, Barres O, Delus C, Villiéras F (2016) Characterisation of suspended particulate matter in the Moselle River (Lorraine, France): evolution along the course of the river and in different hydrologic regimes. J Soils Sediments 16:1625-1642

Luoma SN, Rainbow PS (2008) Metal contamination in aquatic environments - science and lateral management. Cambridge University Press, Cambridge

Ma Y, Qin Y, Zheng B, Zhang L, Zha Y (2015) Seasonal variation of enrichment, accumulation and sources of heavy metals in suspended particulate matter and surface sediments in the Daliao river and Daliao river estuary, Northeast China. Environ Earth Sci 73:5107-5117

Martin J-M, Meybeck M (1979) Elemental mass-balance of material carried by major world rivers. Mar Chem 7:178-206

Middelkoop H (2000) Heavy-metal pollution of the river Rhine and Meuse floodplains in the Netherlands. Neth J Geosci 79:411-428

Moatar F, Abbott BW, Minaudo C, Curie F, Pinay G (2017) Elemental properties, hydrology, and biology interact to shape concentrationdischarge curves for carbon, nutrients, sediment, and major ions. Water Resour Res 53:1270-1287

Nasrabadi T, Ruegner H, Schwientek M, Bennett J, Valipour SF, Grathwohl P (2018) Bulk metal concentrations versus total suspended solids in rivers: time-invariant \& catchment-specific relationships. PLoS One 13:e191314

Owens PN, Batalla RJ, Collins AJ, Gomez B, Hicks DM, Horowitz AJ, Kondolf GM, Marden M, Page MJ, Peacock DH, Petticrew EL, Salomons W, Trustrum NA (2005) Fine-grained sediment in river systems: environmental significance and management issues. River Res Appl 21:693-717

Pawlowsky-Glahn V, Egozcue JJ, Tolosana-Delgado J (2007) Lecture notes on compositional data analysis. http://diobma.udg.edu/ handle/10256/297/

Preusser F (2008) Characterisation and evolution of the River Rhine system. Neth J Geosci 87:7-19

Pulley S, Foster I, Antunes P (2016) The dynamics of sedimentassociated contaminants over a transition from drought to multiple flood events in a lowland UK catchment. Hydrol Process 30:704 719

Quinton JN, Catt JA (2007) Enrichment of heavy metals in sediment resulting from soil erosion on agricultural fields. Environ Sci Technol 41:3495-3500

R Core Team (2017) R: A language and environment for statistical computing. R Foundation for Statistical Computing, Vienna https:// www.R-project.org/

Rijkswaterstaat (2019) WaterInfo. https://waterinfo.rws.nl/

Rondeau B, Cossa D, Gagnon P, Pham TT, Surette C (2005) Hydrological and biogeochemical dynamics of the minor and trace elements in the St. Lawrence River. Appl Geochem 20:1391-1408

Rose LA, Karwan DL, Godsey SE (2018) Concentration-discharge relationships describe solute and sediment mobilization, reaction, and transport at event and longer timescales. Hydrol Process 32: 2829-2844

Rügner H, Schientek M, Milačič R, Zuliani T, Vidmar J, Paunović M, Laschou S, Kalogianni E, Skoulikidis NT, Diamantini E, Majone B, Bellin A, Chiogna G, Martinex E, López de Alda M, Díaz-Cruz MS, Grathwohl P (2019) Particle bound pollutants in rivers: results from suspended sediment sampling in Globaqua River Basins. Sci Total Environ 647:645-652

Salminen R, Batista MJ, Bidovec M, Demetriades A, De Vivo B, De Vos W, Duris M, Gilucis A, Gregorauskiene V, Halamic J, Heitzmann P, Lima A, Jordan G, Klaver G, Klein P, Lis J, Locutura J, Marsina K, 
Mazreku A, O’Connor PJ, Olsson SÅ, Ottesen R-T, Petersell V, Plant JA, Reeder S, Salpeteur I, Sandström H, Siewers U, Steenfelt A, Tarvainen T (2005) Geochemical Atlas of Europe. Part 1 - background information, methodology and maps. Geological Survey of Finland, Otamedia Oy, Espoo

Savenko VS (2007) Chemical composition of sediment load carried by rivers. Geochem Int 45:816-824

Schleichert U, Keller M (1997) Schadstoffgehalte in Schwebstoffen der Hochwasserwelle de Rheins vom April 1994. Bericht 82, Internationale Kommission zum Schutz des Rheins, Koblenz, Germany

Schulz M, Bischoff M (2008) Variation in riverine phosphorus between 1994 and 2003 as affected by land-use and loading reductions in six medium-sized to large German rivers. Limnologica 38:126-138

Smith HG, Blake WH (2016) Sediment fingerprinting in agricultural catchments: a critical re-examination of source discrimination and data corrections. Geomorphology 204:177-191

Smith HG, Karam Lennard AT (2018) Evaluating tracer selection for catchment sediment fingerprinting. J Soils Sediments 18:3005-3019

Syvitski JPM, Vörösmarty C, Kettner AJ, Green P (2005) Impact of humans on the flux of terrestrial sediment to the global coastal ocean. Science 308:376-380

Syvitski JPM, Kettner AJ, Overeem I, Hutton EWH, Hannon MT, Brakenridge GR, Day J, Vörösmarty C, Saito Y, Giosan L, Nicholls RJ (2009) Sinking deltas due to human activities. Nat Geosci 2:681-686

Syvitsky JP, Morehead MD, Bahr DB, Mulder T (2000) Estimating fluvial sediment transport: the rating parameters. Water Resour Res 36: $2747-2760$

Uehlinger U, Wantzen KM, Leuven RSEW, Arndt H (2009) The Rhine river basin. In: Tockner K, Uehlinger U, Robinson CT (eds) Rivers of Europe. Elsevier, London, pp 199-246

Vale C (1990) temporal variations of particulate metals in the Tagus River estuary. Sci Total Environ 97(98):137-154

Van de Meent D, de Leeuw JW, Schenck PA, Salomons W (1985) Geochemistry of suspended particulate matter in two natural sedimentation basins of the river Rhine. Water Res 19:1333-1340
Van der Perk M (2013) Soil and water contamination, second edn. CRC Press, Boca Raton

Van der Weijden CH, Middelburg JJ (1989) Hydrochemistry of the River Rhine: long term and seasonal variability, elemental budgets, base levels and pollution. Water Res 23:1247-1266

Van Dijk PM (2001) Soil erosion and associated sediment supply to rivers: Seasonal dynamics, soil conservations measures, and impacts of climate change. UvA IBED FG, Amsterdam, the Netherlands. http://hdl.handle.net/11245/1.187089

Viers J, Dupré B, Gaillardet J (2009) Chemical composition of suspended sediment in World Rivers: New insights from a new database. Sci Total Environ 407:853-868

Vijver MG, Spijker J, Vink JPM, Posthuma L (2008) Determining metal origins and availability in fluvial deposits by analysis of geochemical baselines and solid-solution partitioning measurements and modelling. Environ Pollut 156:832-839

Vink R, Behrendt H (2002) Heavy metal transport in large river systems: heavy metal emissions and loads in the Rhine and Elbe river basins. Hydrol Process 16:3227-3244

Walling DE (1977) Assessing the accuracy of suspended sediment rating curves for a small basin. Water Resour Res 13:531-538

Walling DE (2006) Human impact on land-ocean sediment transfer by the world's rivers. Geomorphology 79:192-216

Winkels HJ, Blom G, Kroonenberg SB, Lijklema L (1998) Dilution of riverine heavy metal input concentrations by suspension of sediments and algal growth in the IJsselmeer. Water Res 32:2931-2940

Zhao G, Ye S, Yuan H, Ding X, Wang J (2017) Surface sediment properties and heavy metal pollution assessment in the Pearl River Estuary, China. Environ Sci Pollut Res 24:2966-2979

Zwolsman JJG, van Eck GTM (1999) Geochemistry of major elements and trace metals in suspended matter of the Scheldt estuary, southwest Netherlands. Mar Chem 66:91-111

Publisher's note Springer Nature remains neutral with regard to jurisdictional claims in published maps and institutional affiliations. 